\title{
Analyses of genome architecture and gene expression reveal novel candidate virulence factors in the secretome of Phytophthora infestans
}

\author{
Sylvain Raffaele, Joe Win, Liliana M Cano, Sophien Kamoun*
}

\begin{abstract}
Background: Phytophthora infestans is the most devastating pathogen of potato and a model organism for the oomycetes. It exhibits high evolutionary potential and rapidly adapts to host plants. The $P$. infestans genome experienced a repeat-driven expansion relative to the genomes of Phytophthora sojae and Phytophthora ramorum and shows a discontinuous distribution of gene density. Effector genes, such as members of the RXLR and Crinkler (CRN) families, localize to expanded, repeat-rich and gene-sparse regions of the genome. This distinct genomic environment is thought to contribute to genome plasticity and host adaptation.

Results: We used in silico approaches to predict and describe the repertoire of $P$. infestans secreted proteins (the secretome). We defined the "plastic secretome" as a subset of the genome that (i) encodes predicted secreted proteins, (ii) is excluded from genome segments orthologous to the $P$. sojae and $P$. ramorum genomes and (iii) is encoded by genes residing in gene sparse regions of $P$. infestans genome. Although including only $\sim 3 \%$ of $P$. infestans genes, the plastic secretome contains $\sim 62 \%$ of known effector genes and shows $>2$ fold enrichment in genes induced in planta. We highlight 19 plastic secretome genes induced in planta but distinct from previously described effectors. This list includes a trypsin-like serine protease, secreted oxidoreductases, small cysteine-rich proteins and repeat containing proteins that we propose to be novel candidate virulence factors.

Conclusions: This work revealed a remarkably diverse plastic secretome. It illustrates the value of combining genome architecture with comparative genomics to identify novel candidate virulence factors from pathogen genomes.
\end{abstract}

\section{Background}

Phytophthora infestans, the causal agent of the potato and tomato late blight disease, is a successful cosmopolitan plant pathogen. Ever since the Irish potato famine in the middle of the nineteenth century, $P$. infestans has been recognized as one of the most problematic plant pathogens with a global impact on both commercial and subsistence agriculture [1]. This oomycete pathogen is recalcitrant to low input disease management and requires costly chemical treatments to be managed [2]. Part of $P$. infestans success is accounted for by its biological lifestyle and remarkable capacity to rapidly adapt to overcome resistant plants [3]. On infected plants, it continuously produces a large number of asexual spores,

\footnotetext{
* Correspondence: Sophien.Kamoun@sainsbury-laboratory.ac.uk The Sainsbury Laboratory, John Innes Centre, Norwich NR4 7UH, UK
}

including sessile aerially dispersed sporangia and motile zoospores, resulting in polycyclic infections and fast spreading late blight epidemics [4]. In addition, in many regions of the world, $P$. infestans reproduces sexually resulting in increased genetic diversity and extended survival in the field [2]. Based on these biological and epidemiological features, McDonald and Linde concluded that $P$. infestans is a plant pathogen with a high evolutionary potential that can rapidly evolve virulence on resistant plants [3].

Similar to a wide range of animal and plant pathogens, $P$. infestans secretes proteins, termed effectors, that facilitate parasitic colonization by altering host plant physiology and suppressing immunity [5-7]. P. infestans effector proteins target different sites in host plant tissue $[5,6,8]$. First, some effectors act in the extracellular space where they interfere with apoplastic plant defenses. 
Inhibitors of plant extracellular proteases and glucanases are such apoplastic effectors [9-13]. Other effectors, such as small cysteine-rich proteins (SCRs), are also thought to function in the apoplast but their effector activities remain mostly unknown [5,14]. Second, a large number of $P$. infestans effectors, classified as cytoplasmic effectors, are delivered inside host cells using $N$-terminal secretion and host-translocation signals $[5,6,15]$. This is the case for members of the RXLR and Crinkler (CRN) families. A subset of the RXLR effectors is recognized inside plant cells by intracellular immune receptors of the nucleotide-binding leucine-rich repeat (NB-LRR) family (so-called resistance or $\mathrm{R}$ proteins), resulting in the induction of hypersensitive cell death and immunity $[16,17]$.

Evolutionary and comparative genomics analyses revealed that Phytophthora effector genes have undergone accelerated patterns of birth and death evolution with evidence of extensive gene duplication and gene loss in the genomes of $P$. infestans, $P$. sojae, and $P$. ramorum $[15,18-20]$. For instance, in $P$. infestans, only 16 out of the 563 predicted RXLR genes are part of the "core ortholog" gene set (genes residing in 1:1:1 orthologous genome segments between $P$. infestans, $P$. sojae, and $P$. ramorum) [15]. Also, effector genes frequently show signatures of positive selection with extensive nonsynonymous sequence substitutions, leading to high rates of amino acid polymorphisms [19,21,22]. In $P$. infestans, the RXLR and CRN gene families are among the most expanded relative to $P$. sojae and $P$. ramorum [15]. These RXLR and CRN genes mostly populate expanded regions of the $P$. infestans genome that have low gene density and a high abundance of repeats in marked contrast to the housekeeping "core ortholog" gene set that occupy gene-dense and repeat-poor regions [15]. Haas et al proposed that these gene-poor repeat-rich loci are dynamic regions of the genome that underpin the evolutionary potential of $P$. infestans by promoting genome plasticity and enhancing genetic variation of effector genes. Similarly, virulence genes occur in plastic repeat-rich and telomeric regions in various pathogens, which is thought to increase genetic and epigenetic variation and could result in accelerated evolution [23-25].

All known oomycete effectors carry $N$-terminal signal peptides for secretion outside pathogen cells $[5,6,8]$. Although signal peptide sequences are highly degenerate, robust computational prediction algorithms enable a systematic survey of the secreted protein catalog (the secretome) from the genome sequence of a given organism [26]. In particular, the SignalP program that was developed using machine learning methods [27], can assign signal peptide prediction scores and cleavage sites to unknown amino acid sequences with a high degree of accuracy $[28,29]$. This program turned out to be particularly useful for the prediction of effectors from $P$. infestans and other filamentous pathogens as numerous SignalP predictions have been validated experimentally [30-35]. A combination of computational prediction methods was used recently to generate a database of the secretome from 158 fungal and oomycete organisms [36].

In the $P$. infestans genome, a majority of core ortholog genes occur in gene dense regions (GDRs) and are excluded from gene sparse regions (GSRs), which are in contrast enriched in effector genes [15]. This distinctive genome organization offers a unique opportunity to identify novel candidate virulence genes. Furthermore, although the secretome of $P$. infestans includes several hundred candidate effectors belonging to multiple classes, additional families of secreted proteins have not been characterized in much detail [15]. In this study, we used a computational approach to catalog the secretome of $P$. infestans strain T30-4. We then defined and identified the "plastic secretome" as the set of secreted protein genes that (i) do not reside in segments orthologous to $P$. sojae and $P$. ramorum genomes, and (ii) reside in the repeat-rich GSRs. This pipeline resulted in 561 proteins ( $\sim 3 \%$ of the total proteome), of which 398 have already been annotated as effectors by Haas et al. [15]. Because the pipeline identified many in planta-induced genes and $\sim 62 \%$ of all previously predicted $P$. infestans effectors, we concluded that the remaining 163 proteins from the "plastic secretome" are enriched in novel candidate effectors. In particular, we highlight 19 genes that are induced in planta and distinct from known effector families. These analyses implicate trypsin-like serine proteases, berberine-bridge enzymes, carbonic anhydrases, small cysteine-rich proteins and repeat-containing proteins as novel candidate virulence factors.

\section{Results}

\section{Prediction and annotation of Phytophthora infestans secretome}

To identify the secretome of $P$. infestans (set of proteins predicted to be soluble secreted), we predicted signal peptides using the well-validated SignalP v2.0 and v3.0 programs and sub-cellular targeting using TargetP and PSORT (see methods). To ensure stringent standards, only proteins predicted secreted by the four methods were considered further. To remove proteins likely to be retained into $P$. infestans plasma membrane we excluded those for which a transmembrane domain was predicted after the signal peptide cleavage site by TMHMM (see methods). In total, 1,415 of the 18,155 proteins of $P$. infestans were predicted to form the secretome (Additional file 1). To complement existing annotation, we performed detection of protein domains using Pfam and 
Superfamily 1.73 HMM model databases and automated GeneOntology (GO) terms mapping using Blast2GO server (Additional file 1).

\section{Major functional categories enriched in Phytophthora infestans secretome}

To document biological functions enriched in the $P$. infestans secretome, we compared the frequency of occurrence of Pfam domains and GO terms in the secretome to the rest of the proteome using chi-square tests (see methods). We found 15 "Biological process" ontologies, 31 "Molecular function" ontologies and 43 Pfam domains to be enriched in the P. infestans secretome. Seven "Molecular function" ontologies and 4 Pfam domains were depleted from secretome (Figure 1).

Carbohydrate metabolic processes (GO:0005975, also GO:0016052) showed the highest enrichment among biological processes in the P. infestans secretome compared to the rest of the proteome (Figure 1A, green). Related biological processes enriched in the secretome include cell wall modification (GO:0042545) and organization (GO:0007047) processes, as well as catabolism of polysaccharides (GO:0000272), specifically cellulose (GO:0030245) and xylan (GO:0045493). In addition, most of the proteins associated with the sphingolipid metabolic process (GO:0006665) and lysosome organization (GO:0007040) ontologies show sequence similarity to glycosyl hydrolases indicating that these two ontologies are also mostly related to carbohydrate metabolism in P. infestans secretome. Consistently, 15 "molecular function" ontologies directly or indirectly related to sugar metabolism are enriched in the secretome (Figure 1B, green). Sugar binding (GO:0030248, GO:0030246, GO:0005529) and sugar modification activities (GO:0047490, GO:0008810, GO:0004650, GO:0030570, GO:0030599, GO:0004089, GO:0016798, GO:004553) are indeed predominantly found in the $P$. infestans secretome. Furthermore, a majority of proteins associated to glucosylceramidase activity (GO:0004348), and cation binding (GO:0043169) ontologies show similarity to glycosyl hydrolases. Most of the proteins associated to aspartyl esterase activity (GO:0045330) and lyase activity (GO:0016829) show similarity to polygalacturonases and polysaccharide lyases respectively. This enrichment indicates that sensing extracellular sugar and degrading host cell wall are major functions of the Phytophthora secretome as illustrated by several previous studies [37-39]. Finally, 15 Pfam domains enriched in the secretome correspond to enzymes predicted to act on sugars (Figure 1C, green), either as monomers (PF01419 on mannose) or polysaccharides, including cellulose (PF00734, PF01341), $\alpha$ - and $\beta-1,3$ glucans (PF01055, PF00332), ß-1,4 glucans (PF07745), xyloglucans (PF01670), rhamnoglucans (PF00295) and pectin
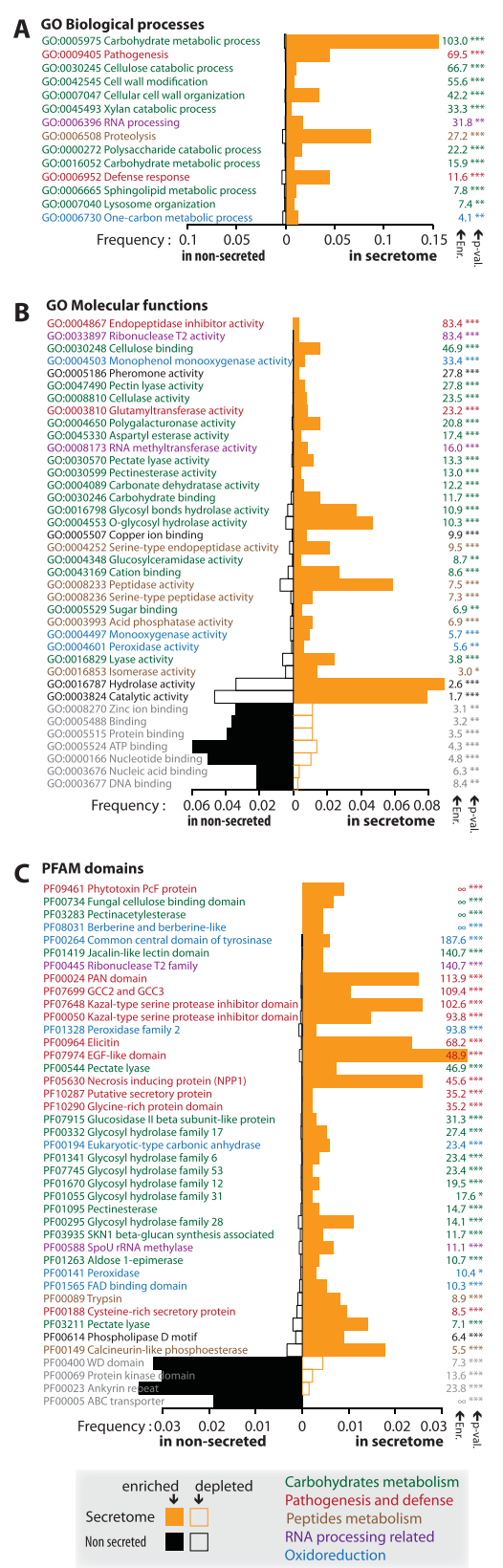

Figure 1 Gene Ontologies and Pfam domains enriched in the Phytophthora infestans secretome. The graphs show the number of proteins annotated with $\mathrm{GO}$ biological process $(\mathbf{A})$, $\mathrm{GO}$ molecular function (B) and Pfam domains (C) and their frequency (number of proteins with annotation/total number of proteins) in the $P$. infestans secretome (yellow bars) and non-secreted proteins (black bars). Only GO and Pfam domains significantly enriched or depleted in the secretome are shown (chi-square test with Bonferroni correction, $p$-value - $p$-val- indicated on the leftmost part of the panels: ${ }^{* * *}, \mathrm{p}$-value $<0.01 ;{ }^{* *}, \mathrm{p}$-value $<0.05 ;{ }^{*}, \mathrm{p}$-value $>0.1$ ). GO and Pfam domains were classified by decreasing enrichment in the secretome (Enr., see methods). Full bars indicate ontology or domain enriched in the secretome, empty bars indicate ontologies or domain depleted from secretome. Ontologies and domains were color-coded for easier reference. Enr., enrichment or depletion fold; p-val, p-value of chi-square test. 
(PF03283, PF00544, PF01095, PF03211). Aldose 1epimerase (PF01263), responsible for interconversion of $\mathrm{D}$-glucose and other aldoses, completes the list of carbohydrate metabolism-related domains enriched in the $P$. infestans secretome.

Pathogenesis (GO:0009405) and defense response (GO:0006952) are biological process ontologies highly enriched in $P$. infestans secretome (Figure 1A, red). The corresponding proteins include some with similarity to elicitins. The molecular function ontology with the highest enrichment in the secretome, endopeptidase inhibitor (GO:0004867), corresponds to Kazal-like serine protease inhibitors, which have been linked to the infection process as apoplastic effectors [10,11,40] (Figure 1B, red). Proteins corresponding to the glutamyltransferase activity (GO:0003810) show similarity to transglutaminase elicitor-like proteins harboring the Pep-13 pathogen associated molecular pattern [41]. The Kazal-type serine protease inhibitor domain is also found among Pfam domains enriched the in secretome (PF07648, PF00050) (Figure 1C, red), together with elicitin domain (PF00964) and necrosis inducing protein domain (PF05630). The Pfam domain showing the highest enrichment in the secretome is the cysteine-rich PcF domain (PF09461) that forms a two-alpha helices domain rich in acidic residues and was reported to cause leaf necrosis [42]. The PAN domain (PF00024) is another cysteine-rich domain enriched in the P. infestans secretome. The PAN domain occurs in the Cellulose-Binding Elicitor-Like protein of Phytophthora parasitica that causes necrosis and activates immunity in plants [43]. Several other Pfam domains enriched in the $P$. infestans secretome are cysteine-rich domains of unclear functions, such as the GCC domain (PF07699), EGF-like domain (PF07974) and the domains of unknown function PF00188 and PF10287. Secreted proteins containing these cysteine-rich domains could play a role in plant infection similar to known small cysteine-rich proteins [14]. Generally, the secretome appears enriched in small (50 to 150 amino acids) proteins and in proteins rich in cysteine $(>5 \%)$ (Additional file 2). Similarly, the $P$. infestans secretome shows higher frequency of proteins with elevated ( $>10$ or $>30 \%$ ) glycine content (Additional file 2). One such example is the IPIB family [44] and its corresponding Pfam domain PF10290 (Figure 1C).

Proteolysis (GO:0006508) is a biological process ontology enriched in the P. infestans secretome (Figure 1A, brown). Consistently, serine type peptidase activity (GO:0004252, GO:0008236) and peptidase activity (GO:0008233) are molecular function ontologies that are also enriched in the $P$. infestans secretome (Figure 1B, brown). Acid phosphatase activity (GO:0003993) regroups another type of hydrolases enriched in the
P. infestans secretome. Pfam domains implicated in peptide hydrolysis, namely trypsin domain (PF0089) and calcineurin domain (PF00149), which show similarity to acid phosphatases, are enriched in the secretome (Figure $1 \mathrm{C}$, brown). In addition, proteins associated to isomerase activity ontology (GO:0016853) mainly show similarity to peptidyl-prolyl cis-trans isomerase or disulfide isomerases. These enzymes are known to accelerate energetically unfavorable cis/trans isomerization of the peptide bond preceding a proline to catalyze protein folding $[45,46]$.

Surprisingly, RNA processing (GO:0006396) appears as a biological process enriched in the $P$. infestans secretome (Figure 1A, purple). Consistently, ribonuclease T2 (GO:0033897) and RNA methyltransferase activity (GO:0008173) are molecular function ontologies enriched in the secretome (Figure $1 \mathrm{~B}$, purple). The ribonuclease T2 (PF00445) and SpoU rRNA methylase (PF00588) are Pfam domains also enriched in the secretome (Figure 1C, purple). RNA cleavage by ribonuclease T2 was shown to be implicated in defense and selfincompatibility processes [47]. Some of these proteins might be effectors that are translocated inside plant cells to alter host transcription or DNA/RNA metabolism. Extracellular nucleases have been described in the fungi Ustilago maydis and Aspergillus spp. [26,48].

Proteins related to oxidoreduction were also particularly abundant in the $P$. infestans secretome. Secreted proteins classified under the one-carbon metabolic process ontology (GO:0006730) (Figure 1A, blue) show similarity to carbonic anhydrase enzymes, catalyzing the conversion of carbon dioxide and water to bicarbonate and protons. The corresponding Pfam domain (Eukaryotic-type carbonic anhydrase, PF00194) is enriched in the $P$. infestans secretome (Figure 1C, blue). Monooxygenase activity (GO:0004497) and monophenol monooxygenase activity (GO:0004503) are molecular function ontologies enriched in the secretome (Figure 1B, blue). Also enriched in the secretome are tyrosinase Pfam domain (PF00264), found in copper monooxygenases involved in the formation of pigments and polyphenolic compounds, and peroxidase Pfam domains (PF00141, PF01328). FAD-binding domain (PF01565) and berberine-like domain (PF08031), which occur in the same set of secreted proteins, complete the list of oxidoreductionrelated domains enriched in the secretome.

Other ontologies enriched in the P. infestans secretome include generic activities such as catalytic (GO:0003824) and hydrolase (GO:0016787) activities, associated largely to predicted glycosyl hydrolases. Copper ion binding (GO:0005507) is another molecular function enriched in the secretome. The pheromone activity (GO:0005186) enriched in the secretome is found in proteins similar to temptins, which mediates 
protein-cell surface contact during fertilization in mollusks [49]. A Phospholipase D (PLD) motif (PF00614) is among the Pfam domains enriched in the P. infestans secretome. Phytophthora PLD activities were proposed to be involved in zoospore encystment [50] and host membrane modification [51] but these secreted PLDs could target host membranes.

Molecular function ontologies depleted from the $P$. infestans secretome (Figure 1B, grey) are generic binding activity (GO:0005488) and more specifically zinc ion binding (GO:0008270), protein binding (GO:0005515) and nucleotide- and nucleoside-binding (GO:0003677, GO:0003676, GO:0000166, GO:0005524). Proteinprotein interaction Pfam domains such as WD (PF00400) and ankyrin repeat (PF00023) are depleted from the $P$. infestans secretome, together with the protein kinase domain (PF00069) and ABC transporter domain (PF00005).

\section{Delimitation of gene dense and gene sparse regions in the $P$. infestans genome}

Because the GSRs of the $P$. infestans genome are highly enriched in RXLR and CRN effector genes, we hypothesized that this property could be used to identify novel effector candidates. First, we needed to determine quantitative parameters that distinguish between GDRs and GSRs. To achieve this, we simulated core ortholog genes content in GDRs and GSRs (as \% of total genes falling in each of these regions) using values of the length ' $L$ ' of flanking intergenic regions (FIRs) between genes ranging from $100 \mathrm{bp}$ to $5 \mathrm{~Kb}$ (Figure 2A, blue and red lines respectively). Genes with both FIRs above L were considered GSR genes, whereas genes with both FIRs below L were considered GDR genes. Core ortholog segregation rate was defined as the difference between the core ortholog content of the GDRs vs. GSRs (green line). For low $L$ values, many core orthologs were excluded from the GDRs since only very tightly packed genes were assigned to them. On the other hand, with larger L values, more genes were assigned to GSRs progressively reducing the proportion represented by the core orthologs. The highest segregation value was obtained for $\mathrm{L}=$ $1.5 \mathrm{~kb}$. At this cutoff, $90 \%$ of the core orthologs were assigned to GDRs (black line) and constituted 55\% of the GDR genes. In contrast, at $\mathrm{L}=1.5 \mathrm{~kb}$, only $17.6 \%$ of GSR genes were core orthologs. We therefore selected $\mathrm{L}=1.5$ $\mathrm{kb}$ for subsequent analyses because this value provided the best segregation between the core ortholog and effector genes into the GDR and GSR genomic compartments.

The $1.5 \mathrm{~kb}$ cutoff delimits four coherent gene pools when combined with the 2-variables binning representation previously performed by Haas et al. [15] (Figure 2B). The GDRs (genes with 5'FIR and 3'FIR $<1.5 \mathrm{~kb}$ ) contain 6689 genes representing $36.8 \%$ of $P$. infestans genes. The GSRs (genes with 5'FIR and 3'FIR > $1.5 \mathrm{~kb}$ ) include 4030 genes, corresponding to $22.1 \%$ of the genes. The other two quadrants group genes with asymmetric FIRs, one shorter than $1.5 \mathrm{~kb}$ and the other one longer. We counted 6216 (34.2\% of the genome) genes residing at the border of GDRs and GSRs. Finally, 1220 genes $(6.7 \%$ of the genome) were omitted because they lack one resolved FIR (locate at one border of scaffolds) or overlap with other genes.

An example of a genome browser view further illustrates the organization of a representative genome region into GDRs and GSRs (Figure 2C). This $80 \mathrm{~kb}$ area of $P$. infestans supercontig 1.13 contains a $60 \mathrm{~kb}$ GSR flanked by short GDRs. As opposed to GSR genes, all the GDR genes belong to genome segments orthologous to the $P$. sojae or $P$. ramorum genomes. All the secreted protein genes in this region occur in the GSR.

Gene sparse regions are enriched in secreted proteins GSRs contain $49.3 \%$ of the secretome genes even though they contain only $22.1 \%$ of the total $P$. infestans genes (Figure 2D). Consistent with previous analyses by Haas et al. [15], GSRs contain $65.8 \%$ of the effector genes, and more specifically $70.2 \%$ of the RXLR and $58.3 \%$ of the CRN genes. Compared to the whole genome, the GSRs show a two-fold enrichment in secreted protein genes, and a three-fold enrichment in effector genes.

In addition, $82.8 \%$ of secretome, $95.1 \%$ of effector, 97.4\% of RXLR and $95.5 \%$ of CRN genes are excluded from the GDRs (occur in both the GSRs and at GDR/ GSR borders). Of the known effectors, only $4.9 \%$ are found in the GDRs, with only 14 out of 540 RXLR effector genes and 6 out of $132 \mathrm{CRN}$ genes.

The "plastic secretome" of $P$. infestans: secretome genes excluded from genome segments orthologous to $P$. sojae or $P$. ramorum and residing in GSRs

One defining feature of $P$. infestans effector genes is that they have significantly diverged from their counterparts in $P$. sojae and P. ramorum and are typically excluded from orthologous segments [15,19]. Orthologous segments (OS) are defined as genome segments derived from a common ancestor without large rearrangements, therefore containing genes showing homology, collinearity, conserved order and orientation in different species [52,53] (Additional file 3). We found that although only $41.9 \%$ (7948) of the total genes and $65.7 \%$ of the secretome genes are excluded from segments orthologous between at least two of the examined Phytophthora species, this proportion reaches $89.1 \%$, $93.8 \%$ and $96.6 \%$ for all effector, RXLR and CRN genes, respectively (Figure 3A). We therefore hypothesized that we could significantly enrich in candidate effector genes using the combination of three criteria: (i) secreted protein, 


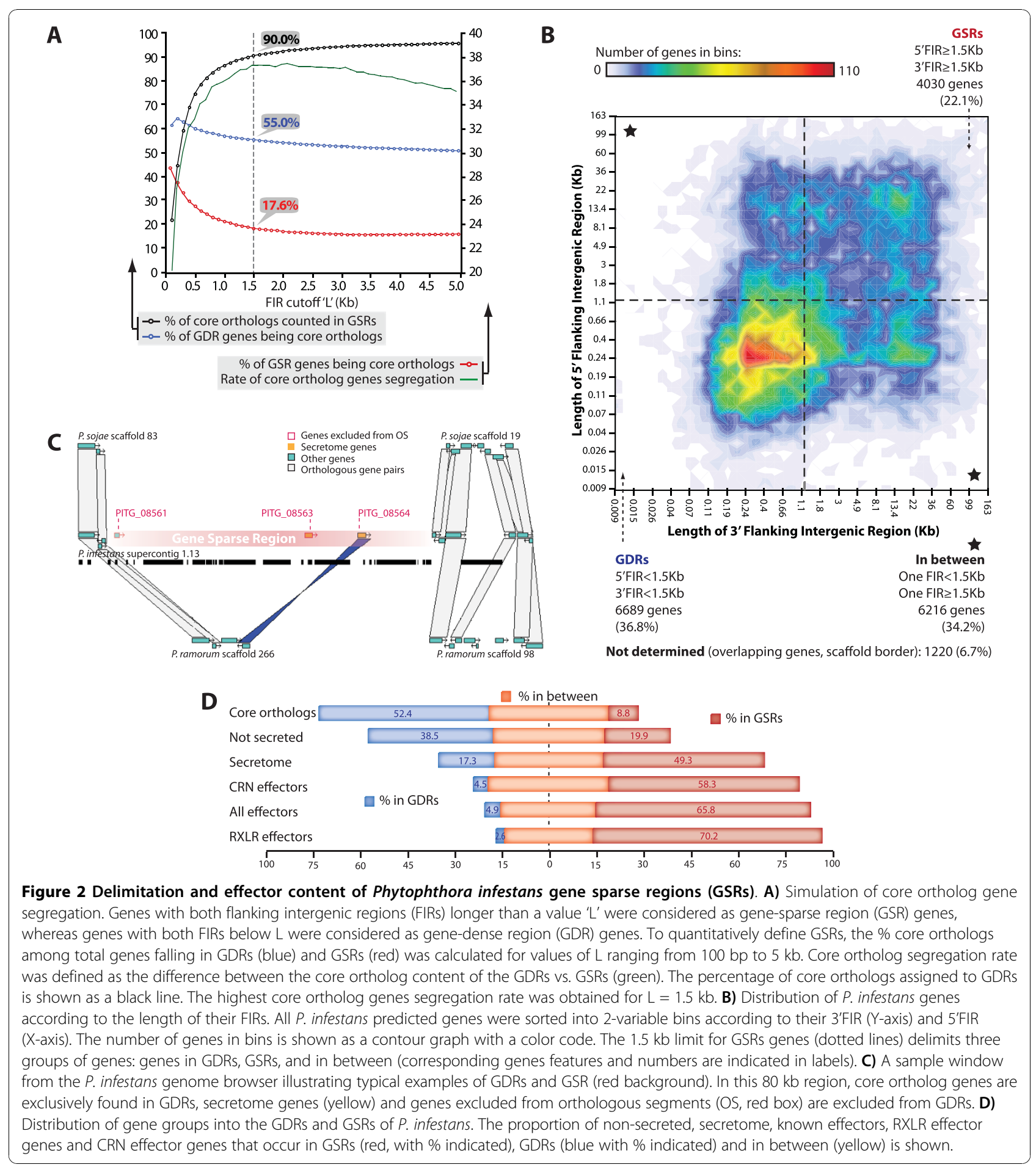

(ii) exclusion from OS, and (iii) occurrence in the GSRs or FIR not determined. In total, 561 genes fulfilled these three criteria (Figure 3B). Genome regions showing frequent re-arrangements, particularly in pathogenic bacteria, have been referred to as "plasticity zones" [54,55]. We therefore refer to the 561 gene set identified here as the "plastic secretome" of $P$. infestans to reflect their localization in plastic genome regions.

The plastic secretome is highly enriched in effectors

Of the 561 genes assigned to the plastic secretome, 398 (70.9\%) are annotated as effectors. Also, even though 
A

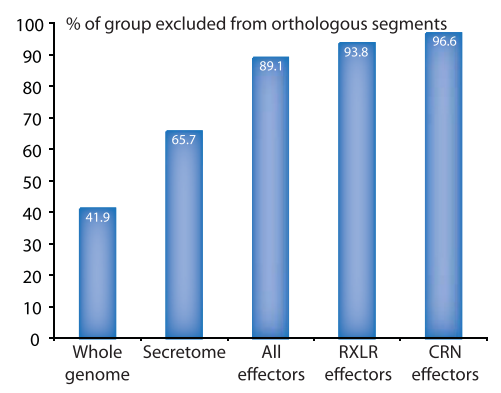

B

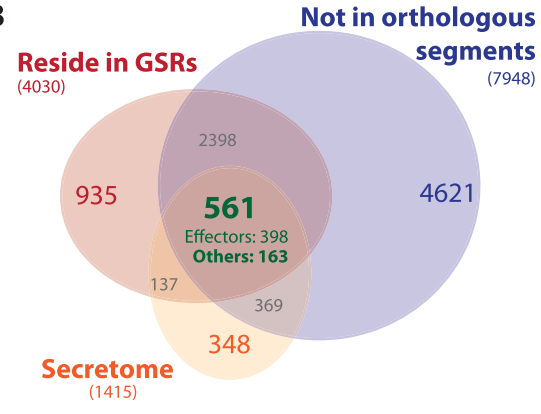

C

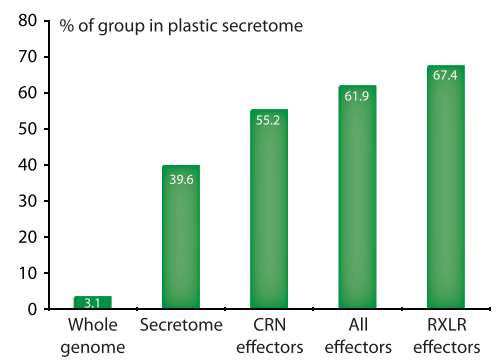

D

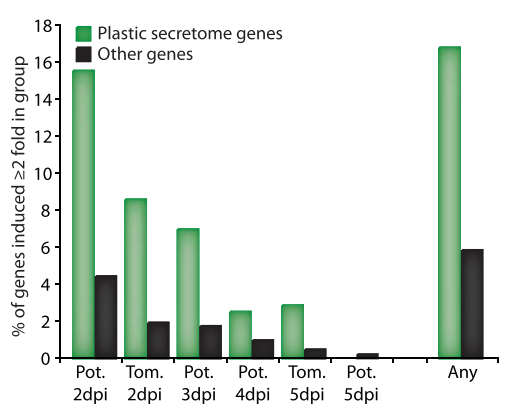

Figure 3 Characterization of the Phytophthora infestans "plastic secretome". A) Frequency of $P$. infestans genes excluded from orthologous segments between $P$. infestans and either the $P$. sojae or $P$. ramorum genome. The proportion (\% of gene group) of all, secretome, known effectors, RXLR effector and CRN effector genes is shown. B) Venn diagram illustrating the number of $P$. infestans genes (i) residing in GSRs and (ii) not in genome segments orthologous between the three Phytophthora species and (iii) belonging to the secretome. This set of three criteria defines the plastic secretome. The $P$. infestans plastic secretome consists of 561 genes: 398 known effector genes and 163 others. C) Percentage of various $P$. infestans gene groups found in the plastic secretome (as a $\%$ of the whole gene group). D) The plastic secretome is enriched in in planta-induced genes. The proportion of either plastic secretome (green) or non-plastic secretome (grey) genes induced in planta is shown. Genes induced at any of the time points tested are the 561 genes correspond to less than $3.1 \%$ of the whole genome, they include $61.9 \%$ of all known effector genes (67.4\% of RXLR genes and $55.2 \%$ of CRN genes, Figure $3 \mathrm{C}$ and additional file 4 ). This clearly indicates that the plastic secretome is highly enriched in effectors and that the remainder 163 genes are likely to be enriched in novel candidate virulence genes.

\section{Genes from the plastic secretome are enriched in genes induced in planta}

To identify candidate virulence genes among the genes from the plastic secretome, we used the whole-genome microarray expression data of $P$. infestans infection time course on potato and tomato [15]. Overall, the genes from the plastic secretome showed a higher proportion of genes induced in planta relative to the remainder of the genes (Figure 3D). In particular, during the early biotrophic phase of infection ( $2 \mathrm{dpi}$ of potato or tomato) 8$16 \%$ of the genes from the plastic secretome are induced relative to less than $4.5 \%$ of the remaining genes (Figure $3 \mathrm{D})$. In total, 95 of the 561 genes from the plastic secretome were classified as induced in at least one of the in planta time points tested (Additional files 1 and 5).

\section{In planta induced genes from the plastic secretome underpin novel candidate virulence genes}

We examined in more details 19 genes from the plastic secretome that have not been previously annotated as effector genes and are induced in planta (Table 1, Additional file 6). Five candidates were annotated as cell wall degrading enzymes (CWDEs): PITG_02545 and PITG_08563 show similarity to pectin lyases, PITG_20953 has an aldose 1-epimerase domain found in some groups of glycoside hydrolases, PITG_22758 is related to arabinofuranosidase, and PITG_22899 has a Jacalin-like lectin domain predicted to bind mannose. Four candidates have other predicted enzymatic activity, including trypsin-like serine protease activity (PITG_02700), oxidoreductase activity (PITG_02930 berberine-bridge enzyme and PITG_18284 carbonic anhydrase) and putative mannose processing activity (PITG_22638). Two candidates are effector-like proteins: PITG_23138 is a truncated RXLR effector that was missed in earlier annotations [15] and PITG_16958 possess the Pep13 motif found in transglutaminase elicitors. Three candidates are repeat-containing proteins (RCPs): PITG_06957 and PITG_17477 have glycine-rich motifs while PITG_06212 harbors lysine-rich repeats. Two candidates are small cysteine-rich proteins (SCRs, PITG_04202, PITG_07213) not previously described. Finally, three candidates (PITG_01659, PITG_07586, PITG_21363) do not have significant similarities to known proteins and sequence motifs. Some of these candidates are described in more details hereafter. 
Table 1 Main features of the 19 novel candidate virulence genes from $P$. infestans plastic secretome

\begin{tabular}{|c|c|c|c|c|c|}
\hline Gene & FIRs $(K b)^{a}$ & Swissprot BlastP (e-value) ${ }^{b}$ & Pfam (e-value) ${ }^{c}$ & $\begin{array}{l}\text { IF } 2 \\
\text { dpid }^{d}\end{array}$ & Comments $^{\mathrm{e}}$ \\
\hline PITG_01659 & $\begin{array}{l}2248- \\
24885\end{array}$ & No hit & No hit & $2.0 x$ & \\
\hline PITG_02545 & $\begin{array}{l}1657- \\
14983\end{array}$ & Pectinesterase $\left(7 e^{-63}\right)$ & PF01095 Pectinesterase $\left(1 e^{-48}\right)$ & $5.7 x$ & CWDE \\
\hline PITG_02700 & $\begin{array}{c}13752- \\
14329\end{array}$ & Chymotrypsinogen B2 $\left(5 e^{-22}\right)$ & PF00089 Trypsin $\left(1 e^{-41}\right)$ & $3.5 x$ & Detailed in Figure 4 \\
\hline PITG_02930 & $6988-2141$ & 6-hydroxy-D-nicotine oxidase $\left(2 e^{-13}\right)$ & $\begin{array}{l}\text { PF01565 FAD binding }\left(2 e^{-20}\right) \text { PF08031 } \\
\text { BBE }\left(9 e^{-08}\right)\end{array}$ & $6.5 x$ & Detailed in Figure 5 \\
\hline PITG_04202 & $\begin{array}{l}8616- \\
13236\end{array}$ & No hit & No hit & $9.8 x$ & $\begin{array}{l}\text { Detailed in Figure } 7 \text { SCR (94aa, } \\
6.4 \% \text { C) }\end{array}$ \\
\hline PITG_06212 & $\begin{array}{l}26186- \\
23867\end{array}$ & No hit & No hit & $3.5 x$ & $\begin{array}{l}\text { Detailed in Figure } 8 \text { RCP ( } 232 \\
\text { aa, } 11.2 \% \text { G) }\end{array}$ \\
\hline PITG_06957 & $\begin{array}{c}24029- \\
3888\end{array}$ & No hit & No hit & $2.1 x$ & $\begin{array}{l}\text { Detailed in Figure } 8 \text { RCP (247aa, } \\
21.5 \% \mathrm{G})\end{array}$ \\
\hline PITG_07213 & $\begin{array}{l}3344- \\
18922\end{array}$ & $\begin{array}{l}\text { HEAT repeat-containing protein } 1 \\
\text { homolog }\left(3 \mathrm{e}^{-04}\right)\end{array}$ & No hit & $2.6 x$ & Secreted SCR (114 aa, 6.1\% C) \\
\hline PITG_07586 & $\begin{array}{l}14222- \\
25733\end{array}$ & No hit & PB012569 $\left(8 \mathrm{e}^{-07}\right)$ & $2.6 x$ & \\
\hline PITG_08563 & $\begin{array}{c}29269- \\
8440\end{array}$ & Probable pectin lyase $\mathrm{F}-2\left(4 \mathrm{e}^{-56}\right)$ & $\begin{array}{l}\text { PB000314 }\left(4 . e^{-20}\right) \text { PF00544 Pectate } \\
\text { lyase C }\left(6 \mathrm{e}^{-12}\right)\end{array}$ & $2.0 x$ & CWDE \\
\hline PITG_16958 & $\begin{array}{l}6840- \\
15261\end{array}$ & No hit & PB013434 Pfam-B_13434 (7e $\left.\mathrm{e}^{-154}\right)$ & $9.8 x$ & $\begin{array}{l}\text { Pep13 motif of transglutaminase } \\
\text { elicitor }\end{array}$ \\
\hline PITG_17477 & ND - 5531 & No hit & No hit & $2.0 x$ & $\begin{array}{l}\text { Detailed in Figure } 8 \text { RCP (374aa, } \\
36.1 \% \mathrm{G} \text { ) }\end{array}$ \\
\hline PITG_18284 & $35643-N D$ & Carbonic anhydrase $\left(2 \mathrm{e}^{-21}\right)$ & PF00194 Carbonic anhydrase $\left(7 \mathrm{e}^{-30}\right)$ & $5.3 x$ & Detailed in Figure 6 \\
\hline PITG_20953 & $7474-9088$ & $\begin{array}{l}\text { Putative glucose-6-P 1-epimerase } \\
\left(8 e^{-29}\right)\end{array}$ & PF01263 Aldose epimerase $\left(5 e^{-22}\right)$ & $2.0 x$ & CWDE \\
\hline PITG_21363 & $33627-N D$ & No hit & No hit & $3.5 x$ & \\
\hline PITG_22638 & $N D$ - ND & $\begin{array}{l}\text { Mannose-P-dolichol utilization defect } \\
1\left(2 \mathrm{e}^{-11}\right)\end{array}$ & PF04193 PQ-loop $\left(3 e^{-13}\right)$ & $2.0 x$ & \\
\hline PITG_22758 & $\begin{array}{c}108426- \\
12121\end{array}$ & $\begin{array}{l}\text { Alpha-N-arabino-furanosidase B } \\
\left(4 \mathrm{e}^{-102}\right)\end{array}$ & $\begin{array}{l}\text { PF09206 Alpha-L-arabino- } \\
\left.\text { furanosidase B (7e } e^{-127}\right)\end{array}$ & $2.8 x$ & CWDE \\
\hline PITG_22899 & $\begin{array}{l}2414- \\
21611\end{array}$ & No hit & PF01419 Jacalin $\left(3 e^{-09}\right)$ & $4.6 x$ & CWDE \\
\hline PITG_23138 & $\begin{array}{c}32957- \\
16047\end{array}$ & No hit & No hit & $2.5 x$ & Truncated RXLR effector \\
\hline
\end{tabular}

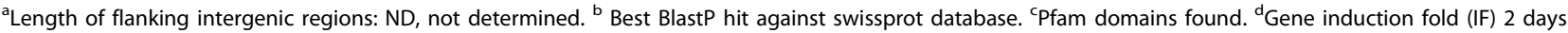
post inoculation (dpi) in potato: expressed as fold of gene expression in mycelia. ${ }^{e}$ aa, amino-acid, \% of cysteine or glycine residues indicated in some cases, CWDE, Cell Wall Degrading Enzyme, SCR, RCP.

\section{Secreted trypsin-like serine proteases related to glucanase inhibitor proteins}

PITG_02700 encodes a predicted trypsin-like serine protease related to Glucanase Inhibitor Proteins (GIPs), which are catalytically inactive proteases that function as apoplastic effectors [9,13]. PITG_02700 belongs to a family of 19 paralogs in $P$. infestans among which 11 are predicted to be secreted (Figure 4A). Only two out of the 19 corresponding genes reside in GDRs (Figure 4B). Unlike the GIPs, the catalytic triad of PITG_02700 is intact suggesting a functional serine protease (Figure 4A). Similar to some GIP genes (Figure 4C), PITG_02700 and its closest paralogs PITG_02704 and PITG_21623 are induced in planta at 2 dpi (Figure 4D).

\section{Berberine bridge enzymes}

PITG_02930 has similarity to berberine bridge enzyme (BBE) genes. BBEs are flavoenzymes related to oligosaccharide oxidases found in archaea, bacteria, plants and fungi. They are involved in the generation of reactive oxygen species and in the synthesis of alkaloids in plants. Five BBE isoforms were predicted in the P. infestans genome, all of which harbor a predicted signal peptide. To gain insights into the impact of sequence polymorphisms on the activity of these enzymes, we aligned the BBE sequences to well characterized homologs from plants and fungi (Figure 5A, Additional file 7) and modeled the 3D structure of P. infestans BBEs (Figure $5 \mathrm{~B})$. All five $P$. infestans BBEs possess the three 


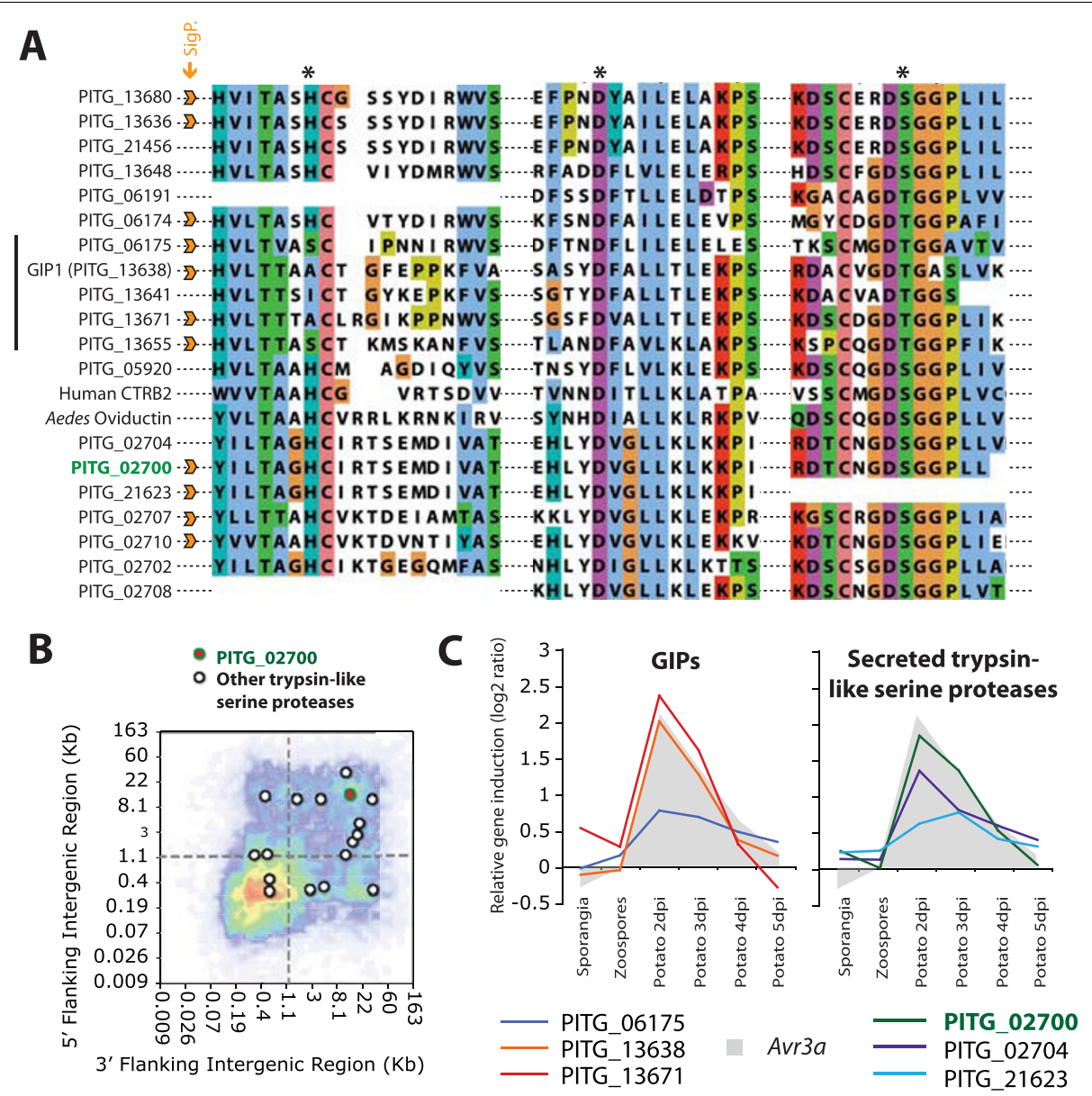

Figure 4 PITG_02700: Trypsin-like serine protease. A) Multiple sequence alignment showing the sequence similarity between PITG_02700 and its paralogs and well-characterized human and Aedes homologs. Regions spanning the catalytic triad (indicated by *) are shown. Proteins belonging to the $P$. infestans secretome are labeled with a signal peptide (SigP.) icon. GIP1, Glucanase Inhibitor Protein 1. B) Position of PITG_02700 and other P. infestans trypsin-like serine proteases on the FIR heat map (Figure 2B). C) in planta expression pattern of three in plantainduced GIP-like genes (left) and three other secreted serine protease genes (right), including PITG_02700. Expression of the effector gene Avr3a is given as a reference. Dpi, days post inoculation.

residues required for $\mathrm{FAD}$ cofactor binding in fungal glucooligosaccharide oxidases (GOOX, related to BBEs, Figure $5 \mathrm{~A}$ ) and show a good conservation of the FADbinding and $\mathrm{BBE}$ domains compared to their plant and fungal counterparts (Figure 5A and 5B, '2' and ' 4 '). Polymorphic residues within the $P$. infestans $\mathrm{BBE}$ clade are mostly found in the sugar-binding region (Figure 5A and 5B ' 1 '). The substrate binding groove region of Phytophthora BBEs (Figure 5A and $5 \mathrm{~B}$ ' 4 ') is divergent from BBEs in other species. The binding groove is widely open in fungal GOOX presumably to accommodate a range of substrates. In contrast, the binding groove in the $P$. infestans modeled BBE is largely obstructed by a coil of amino acids running from one side to the other of the binding pocket (Figure 5A and 5B, ' 3 '). These observations suggest that $P$. infestans BBEs may have evolved to recognize a distinct set of substrates relative to their fungal and plant counterparts. $P$. infestans $\mathrm{BBE}$ genes are all excluded from GDRs (Figure 5C) and are either weakly (PITG_02935, PITG_06585) or strongly (PITG_02930, PITG_02928, PITG_06591) induced at 2 dpi in planta (Figure 5D).

\section{Alpha carbonic anhydrases}

PITG_18284 was annotated as an alpha-carbonic anhydrase $(\alpha-C A)$. The $P$. infestans genome encodes 13 predicted $\alpha$-CAs among which seven belong to the secretome. To explore the structural properties of the $P$. infestans $\alpha$-CAs, we aligned their sequences to the closest human homologs and to tobacco NEC3 $\alpha$-CA (Figure $6 \mathrm{~A}$, Additional file 7), and modeled the 3D structure of PITG_18284 and PITG_17842 (Figure 6B). When compared to human and tobacco homologs, $P$. infestans $\alpha$-CAs show a conserved core surrounding the active 


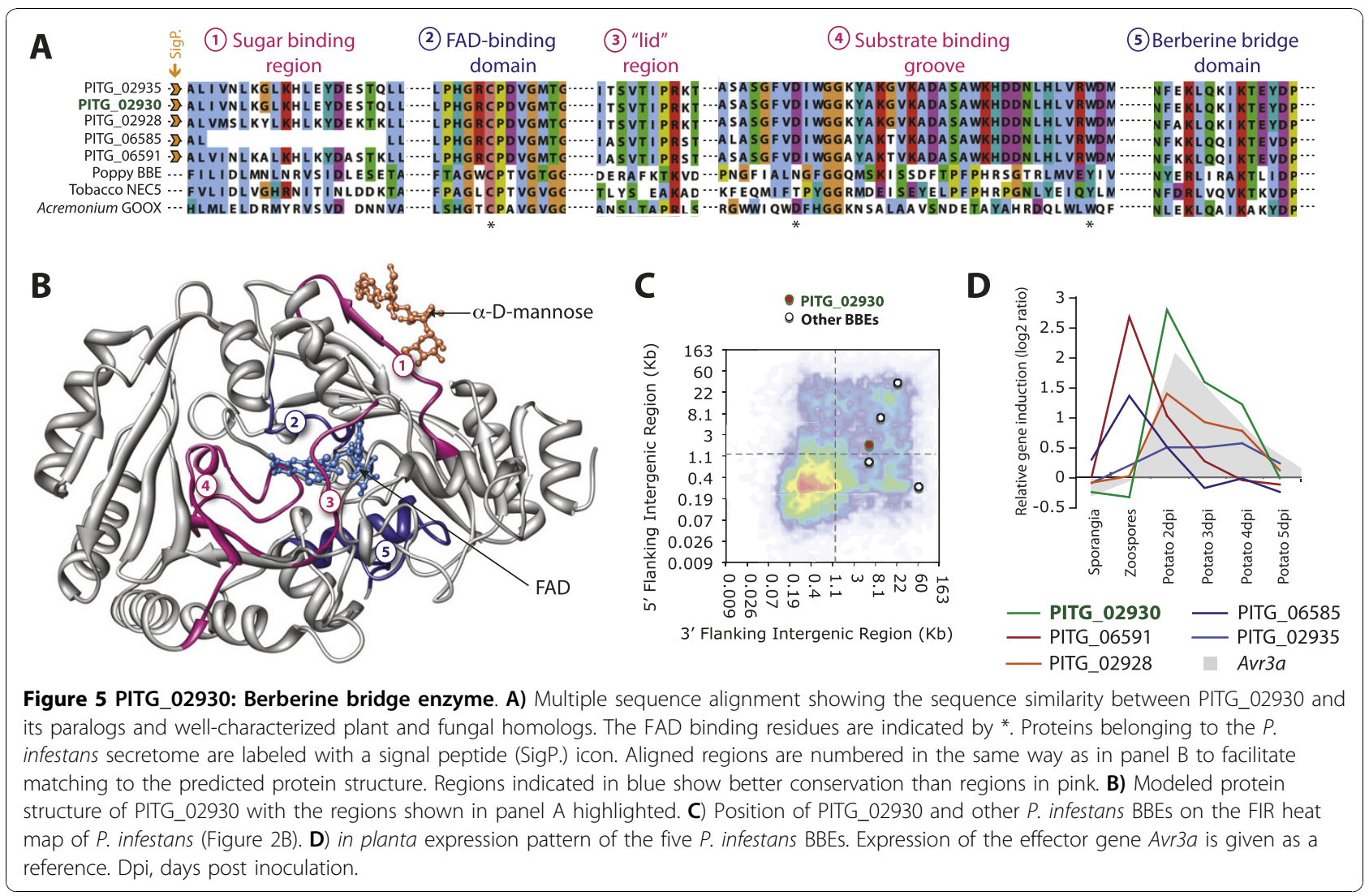

site (Figure 6A and 6B, '2' SEHT motif of '3', '4' and '7') with conserved catalytic residues (with the exception of PITG_08497). On the contrary, regions at the surface of the enzyme are variable between $P$. infestans $\alpha$-CAs and differ from human and tobacco enzymes (' 1 ', ' 5 ' and ' 6 ', residues surrounding the SEHT motif of ' 3 '). This notably results in the absence in the $P$. infestans enzymes of an alpha helix gating the entry of the zinc-binding pocket in human enzymes. Residues in this alpha helix are in close proximity with sulfonamide inhibitor in human models suggesting that $P$. infestans $\alpha$-CAs may have evolved alternative docking properties at the entrance of the zinc-binding groove. All $P$. infestans $\alpha$ CA genes, except PITG_08497, are excluded from GDRs (Figure 6C). Whereas the $P$. infestans $\alpha$-CA genes that encode non-secreted enzymes are not induced in planta (PITG_17808 and PITG_17844 in Figure 6D), most of the genes encoding secreted $\alpha$-CAs are strongly induced either early (PITG_17842 and PITG_18284) or late (PITG_14412) during plant infection (Figure 6D).

\section{Novel small cysteine-rich (SCR) proteins}

Many filamentous pathogen effectors encode small ( $<150$ amino acids) secreted proteins with an even number of cysteine residues that form disulfide bridges [5]. We found 265 small (50 to 150 amino-acids) cysteine- rich ( $>5 \%$ of sequence) in P. infestans (Additional file 8 ). Among them, 59 are predicted to be secreted, $17 \%$ of which are induced in planta (Additional file 8). In particular, PITG_04202 is a gene from the plastic secretome that encodes a 94 amino acid SCR with six cysteines (Figure 7). It has one close paralog (PITG_04213) that encodes a 99 amino acid protein with the six cysteine residues conserved. PITG_04202 is induced in planta during the biotrophic phase similar to previously studied SCR effectors such as SCR91, SCR50, and SCR58.

\section{Repeat containing proteins (RCPs)}

Many microbial adhesins are repetitive proteins with different types of repeats, such as glycine-rich repeats. Some oomycete repeat containing proteins are secreted proteins that are thought to function in adhesion, and include $P$. infestans mucin-like protein CAR90 [56], IPIB [44], and M96 mating-specific proteins [57]. Several of the $P$. infestans genes from the plastic secretome that are induced in planta encode repeat-containing proteins not described to date. PITG_17477 encodes a 374 amino acid protein with more than $30 \%$ glycine residues due to 48 [VA][GS]GG repeats. It has one close paralog in P. infestans, PITG_05807 (Figure 8A). The PITG_17477 gene is induced during the biotrophic phase of potato infection (Figure 8B). 

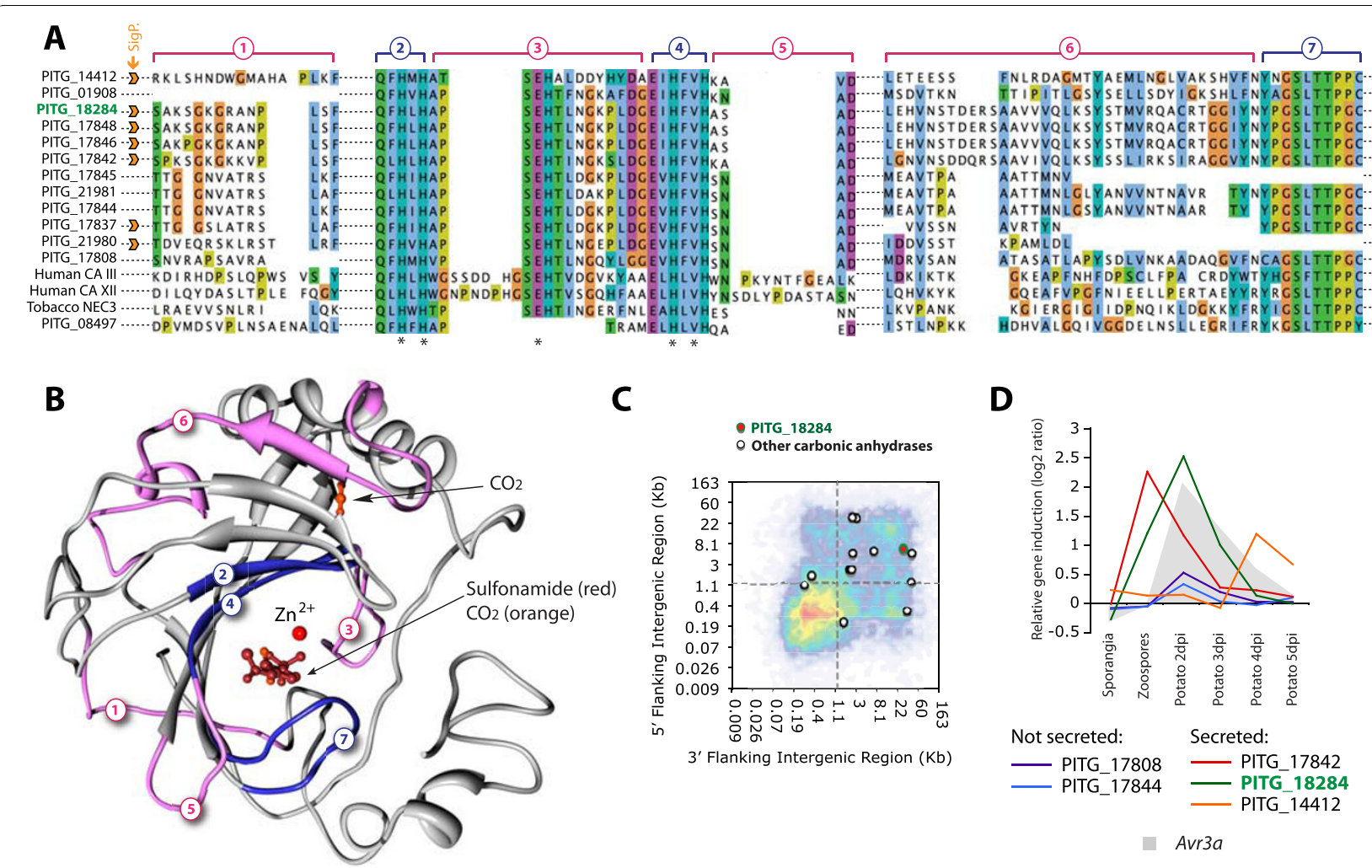

C

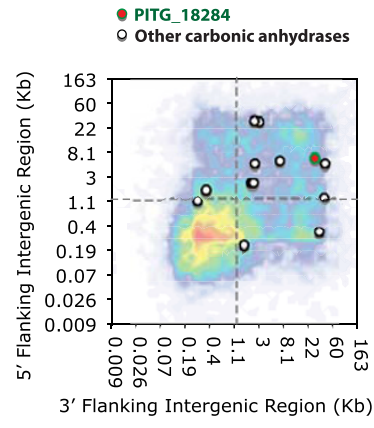

D

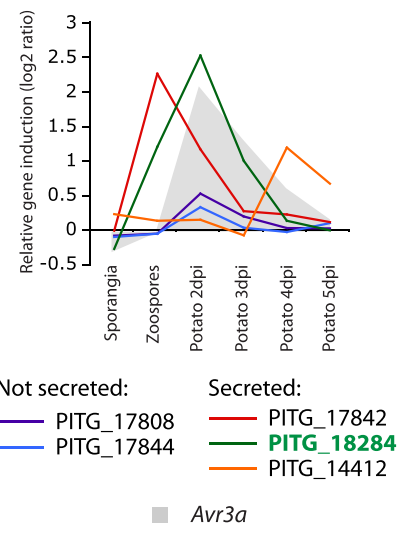

Figure 6 PITG_18284: Alpha-carbonic anhydrase. A) Multiple sequence alignment showing the sequence similarity between PITG_18284 protein from the plastic secretome and its paralogs and well-characterized plant and human homologs. The $\mathrm{CO}_{2}$ binding residues are indicated by *. Proteins belonging to the $P$. infestans secretome are labeled with a signal peptide (SigP.) icon. Aligned regions are numbered in the same way in panel $B$ to facilitate matching the sequence to the predicted protein structure. Regions indicated in blue show better conservation than regions in pink. B) Modeled protein structure of PITG_18284 with the regions shown in panel A highlighted. C) Position of PITG_18284 and other $P$. infestans $\alpha$-CA on the FIR heat map of $P$. infestans (Figure 2B). D) in planta expression pattern of five $P$. infestans $\alpha$-CAs. Non-secreted $\alpha$ CAs are not induced in planta (PITG_17808 and PITG_17844), whereas secreted $\alpha$-CAs show early (PITG_17842 and PITG_18284) or late induction (PITG_14412). Expression of the effector gene Avr3a is given as a reference. Dpi, days post inoculation.

PITG_06957 encodes a 247 amino acid protein with 53 glycine residues organized in 22 imperfect GGSxET repeats (Figure 8A). This gene lacks paralogs in $P$. infestans, and this class of repeats is absent from other $P$. infestans proteins. PITG_06957 is induced two-fold during the biotrophic phase of potato infection (Figure 8B).

Besides Glycine-rich repeat containing proteins, PITG_06212 is a 232 amino acid protein that contains 64. lysine residues organized in $11 \mathrm{KKE}$ repeats followed by 10 DxGEKSKKx repeats (Figure $8 \mathrm{~A}$ ). The same repeat pattern was observed in the sequence of the protein encoded by the paralogous gene PITG_13157. PITG_0621 is induced during the biotrophic phase of potato infection (Figure 8B).

\section{Discussion}

We exploited genome organization to augment other criteria for selection of candidate virulence genes in the oomycete plant pathogen $P$. infestans. Based on the work of Haas et al. (2009), genome organization appears to be a good indicator of virulence genes in P. infestans. Can this strategy be extended to explore and identify novel effectors from other pathogens? Effector genes often occur in plastic genomic regions. A remarkable example is the plant pathogenic fungus Leptosphaeria maculans in which the AvrLm1, AvrLm6 and AvrLm4-7 effector genes reside in $100 \mathrm{~kb}$ or larger AT-rich gene-poor isochores [58-60]. In other plant pathogenic fungi, such as Alternaria alternata [61], Mycosphaerella graminicola [62], and Fusarium graminearum [63], some effector genes are carried in conditionally dispensable chromosomes. Localization of effectors in plastic genome regions also extends to animal pathogens. Host-translocated effectors from Plasmodium are often found near telomeric regions of chromosomes [25]. These specific effector genome niches in eukaryotic pathogens are reminiscent of the highly variable bacterial pathogenicity islands that carry clustered translocation machinery and effector genes [64]. In summary, localization of effector genes to dedicated plastic regions of pathogen genomes is a frequent occurrence. The strategy we 


\section{A PITG_04202 MKVLI VFAAVATLLMPV QCAG I G FDNKYEGSGFLTADFTQK SCAS
PITG_04213 MKVLIVFAAVATLLMPVHGVLRQCAGI GPDNRYEGSGFTADFTQKSCAS

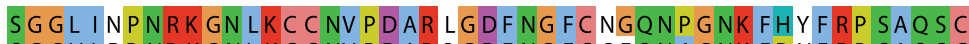 \\ $S G G V I D P N R K G N L K C$ CNVPDARQGDFNG FCSEQNAGNK FPNFRP SAQSC}

B

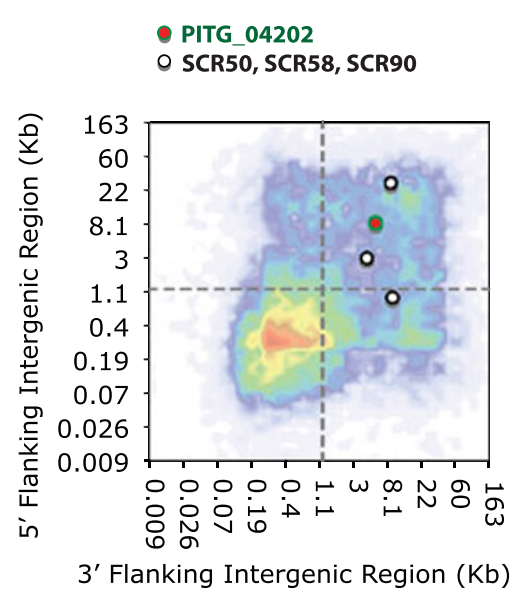

C

PITG_04202

PITG_23077 (SCR91)

PITG_23123 (SCR50)

PITG_23156 (SCR58)

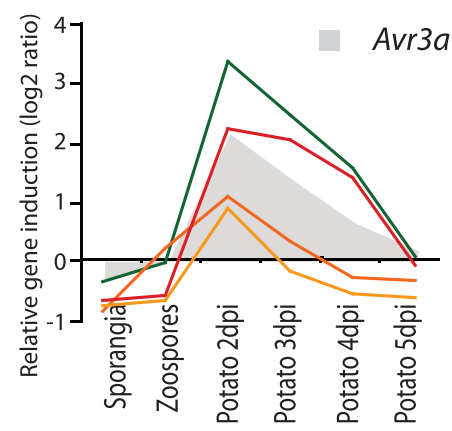

Figure 7 PITG_04202: Small cysteine rich proteins (SCR). A) Pairwise sequence alignment of SCR PITG_04202 and its closest paralog. B) Position of PITG_04202 and known SCRs genes on the FIR heat map of P. infestans. C) in planta expression pattern of known SCR genes (SCR58, SCR91 and SCR50) and PITG_04202. Expression of the effector gene Avr3a is given as a reference. Dpi, days post inoculation.

applied in this work enabled the identification of previously overlooked candidate virulence genes and is in principle applicable to a wide range of eukaryotic pathogenic microorganisms.

Plastic genome regions can take several forms such as dispensable chromosomes or telomeric regions. Are there conserved features that characterize plastic genome regions? How can we recognize them? High density of active mobile DNA transposable elements (TEs) can be considered a signature of variable genome regions. TEs have long been considered "selfish genes" for causing chromosomal breaks, deletions, or translocations [65]. But several studies now show that TEs are major drivers of rapid evolution and functional diversification of gene families [66] as well as evolution of gene regulation $[67,68]$. TEs tend to accumulate around genes involved in stress response, defense and response to external cues [66]. The length of the intergenic regions flanking each gene reflects the impact of TEs on local gene density. Analysis of the distribution of FIRs helps to visualize localized and differential TE activity and to identify plastic genome regions [15]. In this regard, $P$. infestans stands out by its dramatic uneven distribution in FIR lengths that results in a clear demarcation of GDRs vs GSRs (Figure 2B). This extreme property of the P. infestans genome allowed us to quantify the degree of association between effector genes and plastic genome regions. Clearly, effector genes almost exclusively reside in GSRs, supporting a contribution of TE activity to effector evolution (Figure 2D).
Among the novel candidate virulence genes we identified, there were two types of oxidoreductases (berberine-bridge enzyme and alpha-carbonic anhydrase). The presence of enzymes catalyzing conversion of rather simple molecules within the plastic secretome of $P$. infestans is perhaps surprising. What role may such catalytic enzymes play in the interaction between $P$. infestans and host plants? How do polymorphisms in these enzymes affect host interactions? BBEs are flavoenzymes that catalyze carbohydrate oxidation in plants, either for the biosynthesis of berberine type alkaloids, or for the generation of hydrogen peroxide $\left(\mathrm{H}_{2} \mathrm{O}_{2}\right)$. Plant BBEs are highly induced during various defense responses, when they may contribute to the oxidative burst leading to cell death, through $\mathrm{H}_{2} \mathrm{O}_{2}$ synthesis. CAs typically function in acid-base balance control by rapidly converting carbon dioxide to bicarbonate. CA activity is also required for the onset of disease resistance in tobacco. Silencing of a CA gene in the plant Nicotiana benthamiana results in enhanced susceptibility to $P$. infestans [69] and a salicylic acid binding protein SABP3 exhibiting CA activity is required for the onset of the hypersensitive response toward the bacterial plant pathogen Agrobacterium tumefaciens [70]. Therefore oxidoreductases might be involved in triggering or enhancing host cell death responses during the necrotrophic phase of $P$. infestans growth. Alternatively, $\mathrm{H}_{2} \mathrm{O}_{2}$ production may contribute to plant cell wall degradation by $P$. infestans. The ability to degrade alkaloids may also contribute to virulence of various plant pathogens [71], 


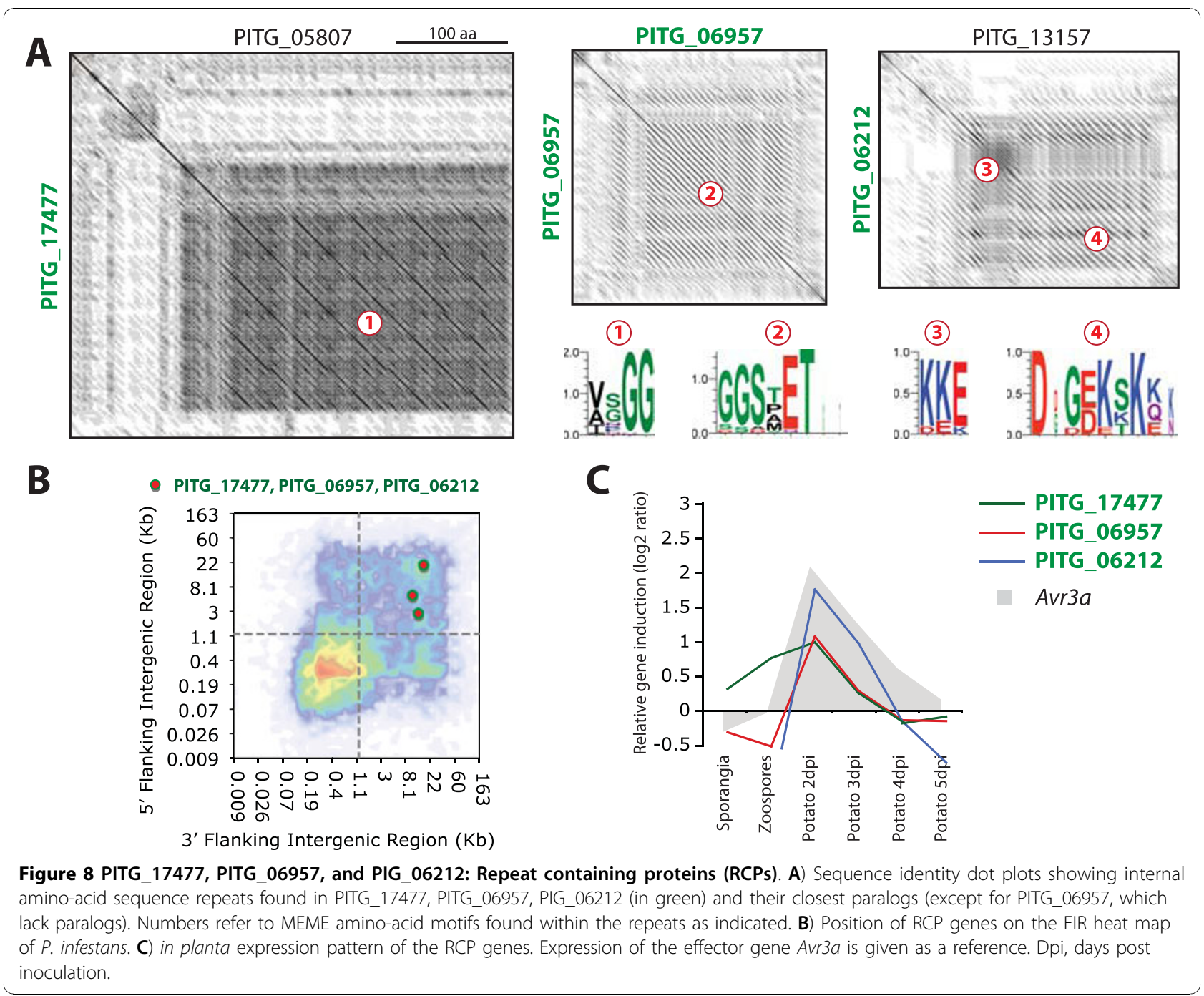

for instance by counteracting antimicrobial properties of plant-synthesized alkaloids (such as berberine) and sulfonamides (such as quinine, potent inhibitors of $\alpha$-CAs) $[72,73]$. In any case, it is possible that evasion of plant inhibitors (e.g. plant-specific sulfonamides) contributes to rapid evolution in $P$. infestans secreted BBE and $\alpha-$ $\mathrm{CA}$ enzymes. Plant secondary metabolites are structurally highly diverse, and their corresponding biosynthetic genes are frequently associated with divergent genome regions $[74,75]$. Plant-pathogen arms race coevolution might result in a parallel highly divergent detoxification arsenal in pathogen genome. The examples of BBE and $\alpha$-CA described here emphasize the need for integrated metabolomic surveys of plant-pathogen interactions.

Cell wall degrading enzymes (CWDEs) are a hallmark of filamentous pathogen secretomes [26,76,77]. A diverse repertoire of secreted CWDEs matches the variety of sugar polymers that make up plant cell walls. Two P. infestans genes from the plastic secretome,
PITG_02524 and PITG_08563, are predicted pectin lyases, which are known in other pathogens as virulence factors that degrade the pectic components of plant cell walls [78]. Another gene from the plastic secretome, PITG_22758, is related to concanavalin A lectins/glucanases, which carry out the acid catalysis of beta-glucans [79] or function in cell recognition in eukaryotes [80]. In plants, lectins show a wide variety of protein structures and sugar binding properties that matches the diversity of sugar molecules [81]. It is therefore reasonable to correlate the diversity of $P$. infestans secreted CWDEs to the complexity of the plant cell wall. But how to explain the high divergence observed in the CWDEs in plastic regions? First, plant cell walls are highly variable from one plant species to another and between different stages of plant development [82]. Therefore secreted CWDEs genes residing in plastic genome regions may have enabled faster adaptation to a new host or tissue (for instance, leaf vs root). Second, 
plants have evolved a number of CWDE inhibitors as a pathogen defense mechanism [83]. Rapid evolution in $P$. infestans secreted CWDEs may have been driven by arms race coevolution with host inhibitors. Third, cell wall degradation products can act as damage-induced molecular patterns (DAMPs) and trigger plant immune responses [84]. P. infestans CWDEs may therefore evolve to minimize DAMP induction. In summary, localization of particular carbohydrate binding protein genes in plastic genomic regions may have contributed to the pathogenic success of $P$. infestans.

It is well accepted that due to metabolic costs and spatial constraints, genome expansion is globally selected against unless it provides an important functional advantage [85]. Although evidence for the contribution of noncoding DNA expansion to gene evolution continues to accumulate, the mechanisms that enable faster gene evolution remain poorly understood. Unlike housekeeping genes, most effector genes show a "patchy" phylogenetic distribution, being present in $P$. infestans but lacking in $P$. sojae and P. ramorum. Similar properties are typical of the virulence genes of a variety of fungal and oomycete pathogens $[6,86]$. This can be due to high rates of mutations, gene loss, copy number variation $(\mathrm{CNV})$, or horizontal gene transfer that are thought to occur more frequently in plastic regions of the genome. One example is the large specific deletion spanning $A v r L m 1$ that is responsible for gain of virulence on $R \operatorname{lm} 1$ plants in $L$. maculans [23]. Similar gene deletions were reported for several fungal plant pathogen avirulence loci, such as Avr9 and avr4E of Clasdosporium fulvum [87], SIX1 of Fusarium oxysporum [88] and Avr1-CO39 and Avr-Pita of Magnaporthe grisea [89,90]. Additionally, an excess of $\mathrm{CNV}$ and increased sequence polymorphisms were noted toward chromosomal ends in Plasmodium spp. [91]. Such genome remodeling might preferentially occur in regions with extensive non-coding DNA because of reduced deleterious consequences to cis-linked genes [92]. Another hypothesis is that longer flanking regions enable the development of more tightly and accurately regulated expression patterns [65,92], possibly through epigenetic variation $[90,93]$. Future comparative genomics of clusters of closely related pathogen species will help to further clarify the mechanisms underlying rapid evolution of plastic genome regions and to test these various hypotheses.

\section{Conclusions}

In this study, we predicted and annotated the secretome of the Irish potato famine pathogen $P$. infestans using in silico approaches. We quantitatively described $P$. infestans genome organization by delimiting gene dense and gene sparse regions. We used genome organization as a novel approach that augments previously established criteria to mine for candidate virulence factors. Occurrence of secreted protein genes in GSRs, in combination with comparative genomics and transcriptomics, implicated 19 previously overlooked genes in virulence. These include cell wall degrading enzymes, trypsin-like serine protease, carbonic anhydrase, berberine bridge enzyme, several repeat containing proteins, and small cysteine-rich proteins.

\section{Methods}

\section{Identification of putative secreted proteins}

Signal peptide predictions were performed following the methods of Torto et al. (2003) [30] and Win et al. [19]. The 18,155 proteins predicted by Haas et al. (2009) [15] from the $P$. infestans T30-4 genome assembly were submitted to SignalP v2.0 [94]. A SignalP HMM score cutoff of $\geq 0.9$ was used (2,228 proteins recovered). This set of 2228 proteins was submitted to SignalP3.0 [95], RPSP [96], TargetP [97], WolfPSort [98] and TMHMM [99] (Additional file 1). Proteins showing (i) SignalP2.0 HMM score $\geq 0.9$ and (ii) SignalP3.0 NN Ymax Score $\geq$ 0.5 and (iii) SignalP3.0 NN D-score $\geq 0.5$ and (iv) SignalP3.0 HMM S probability $\geq 0.9$ and (v) TargetP predicted localization "Secreted" (S) and (vi) most probable PSort location "extracellular" (extr.) and no TMHMM predicted transmembrane domain after signal peptide cleavage site were considered as $P$. infestans secretome.

\section{Enrichment analyses}

Pfam [100] and Superfamily 1.73 [101] with default parameters were used to complement the annotation of the secreted proteins. Gene Ontology (GO) terms mapping was performed on $P$. infestans proteome using Blast2GO [102] with default parameters and GO sorted by domain (Additional file 1). The number of occurrences of each Pfam domain, Molecular function GO and Biological process GO found in secretome was calculated among secretome proteins and the rest of the proteome. Frequencies are given as the number of occurrences over the total number of Pfam domain or GO hits among secreted or non-secreted proteins. Enrichment fold correspond to frequency in secretome over frequency in the rest of the proteome. Depletion fold (1 over enrichment fold) is given for domains/ ontologies depleted from secretome. Significance of enrichment/depletion is assessed by a chi-square test with Bonferroni correction for multiple testing. Only Pfam domains with enrichment $\mathrm{p}$-value $\leq 0.1$ and at least one hit with e-value $\leq 10 \mathrm{e}^{-05}$ and GO with enrichment $\mathrm{p}$-value $\leq 0.1$ are reported in figure 1 .

\section{Identification of genes belonging to orthologous segments}

Genes belonging to orthologous segments were identified in Haas et al. [15]. Briefly, regions of conserved 
collinear gene order between $P$. infestans, $P$. sojae and $P$. ramorum genomes were computed using DAGchainer 30 considering only the relative order of the genes along each scaffold [103]. Only orthologs defined by OrthoMCL 24 [104] were used as anchors for collinear blocks. Collinear blocks were defined between each pair of the three Phytophthora genomes. The orthologous segments reported corresponds to the union of blocks obtained from the pairwise comparisons to the other genomes.

\section{Sequences alignments}

Similarity searches were performed using Blastall from NCBI Blast package [105]. Sequences were aligned using Clustal W2 program [106], rendered with Jalview [107] and manually annotated. Protein domains in candidate virulence genes were identified using Pfam [100]. Identity dotplots for Repeat containing proteins were drawn using Dotlet with word size of 7 [108], motifs were found using MEME [109].

\section{Gene expression analysis}

Whole genome expression data used in this work were previously described by Haas et al. [15] and are based on a custom NimbleGen oligonucleotide microarray. $P$. infestans genes were classified as induced when they showed at least a 2 -fold induction during colonization of potato at 2, 3, 4 or 5 days post inoculation (dpi), or tomato at 2 or $5 \mathrm{dpi}$, compared to in vitro grown mycelia. In Figures 4, 5, 6, 7 and 8, gene expression is given as $\log _{2}$ (linear expression in sample/average linear expression in control mycelia).

\section{Protein 3D modeling and structure analysis}

3D structure of PITG_02935, PITG_02930 and PITG_06585 P. infestans BBEs were modeled based on homology with the template protein structures of Acremonium strictum 1ZR6A [110] and Eschscholzia californica 3D2H [111]. The align2d function and 3D modeling in modeler9v7 [112] were used for that purpose. 3D structure of PITG_17842 and PITG_18284 $\alpha$-CA were predicted using similar methods by homology with human 1FLJA [113] and 1JD0A [114]. Rendering of the models was performed with Chimera [115]. To compare protein structures, the models were superimposed by matching $\mathrm{C}, \mathrm{N}$ and $\mathrm{O}$ atoms from residues $\mathrm{H} 94, \mathrm{H} 96$, H119 of 1JD0.A to H92, H94, H111 of PITG_18284 model; C130, D355, W383 of 1ZR6 to C146, D373, W401 of PITG_02930 model; C166, W328, I516 of 3D2D to C146, W311, I487 of PITG_02930 model.

\section{Additional material}

Additional file 1: Complete list of $P$. infestans predicted secretome. Microsoft Excel spreadsheet containing complete list of $P$. infestans secretome genes, including annotation steps, biological processes and biological function categories, genomic and expression data.

Additional file 2: The distribution of $P$. infestans complete proteome and secretome according to protein length, cysteine and glycine content. Graphs showing the distribution of protein length, cysteine and glycine content among $P$. infestans genes.

Additional file 3: Gene conservation in P. infestans plastic secretome. A) The different levels of orthology and conservation for $P$. infestans genes. 5994 P. infestans genes are absent from genome segments orthologous with $P$. sojae and $P$. ramorum genomes, 2396 of them do not have orthologs (1.e- ${ }^{10}$ blastP e-value cutoff) in P. sojae or $P$. ramorum genomes. B) Frequency of $P$. infestans genes with orthologs in $P$. sojae and $P$. ramorum. The level of orthology is given by $\%$ of sequence identity between $P$. infestans protein and its best Blast $P$ hit in $P$. sojae or $P$. ramorum proteome. Frequencies among non-secreted proteins (grey), plastic secretome (green) and other secretome proteins (yellow) are shown.

Additional file 4: Frequency of secretome genes, genes from nonOS, GDR and GSRs. table showing the number and \% of genes from various groups matching specific conditions related to genome environment and secretome features

Additional file 5: Number and frequency of genes induced in planta. table comparing the distribution of genes induced in planta at different time point from the whole genome and the plastic secretome

Additional file 6: Genomic context of the 19 genes from the plastic secretome induced in planta described in details in this manuscript. Figure showing genes, orthologous gene pairs, and repeated sequences in the genomic environment of 19 genes from the plastic secretome.

Additional file 7: Alignments used for 3D modeling of $P$. infestans berberine bridge enzymes and alpha carbonic anhydrase.

Additional file 8: Global analysis of $P$. infestans Small Cysteine-rich proteins. A) Distribution of $P$. infestans proteins according to their length and cysteine content. B) Position of PITG_04202 and other P. infestans secreted SCRs on the FIR heat map. C) Frequency of SCR sequences as a $\%$ of $P$. infestans whole proteome, secretome and non-secreted proteins; frequency of SCR genes induced as a \% of SCR genes in P. infestans whole genome, secretome and non-secretome genes.

\section{Abbreviations}

BBE: Berberine Bridge Enzyme; CA: Carbonic Anhydrase; CNV: Copy Number Variation; CRN: Crinkler effector; CWDE: Cell Wall Degrading Enzyme; DAMP: Damage induced Molecular Pattern; dpi: days post inoculation; FIR: Flanking Intergenic Region; GDR: Gene Dense Region; GIP: Glucanase Inhibitor Protein; GOOX: Glucooligosaccharide oxidase; GSR: Gene Sparse Region; OS: Orthologous Segments; RCP: Repeat-Containing Protein; SCR: Small CysteineRich protein; TE: Transposable Element.

\section{Acknowledgements}

We thank members of the Kamoun lab, David J. Studholme and Brian J. Haas for helpful useful suggestions and four anonymous reviewers for comments that significantly helped improve the quality of this manuscript. This research was supported by the Gatsby Charitable Foundation.

\section{Authors' contributions}

SR carried out most analyses, contributed to the design of the study and drafted the manuscript. JW performed the secretome predictions, provided guidance with some of the analyses and contributed to the writing of the 
manuscript. LC helped with the gene expression analyses and contributed to the writing of the manuscript. SK conceived and designed the study, edited the manuscript and supervised the work. All authors read and approved the final manuscript.

Received: 28 April 2010 Accepted: 16 November 2010

Published: 16 November 2010

\section{References}

1. Kirk WW, Abu-El Samen F, Tumbalam P, Wharton P, Douches D, Thill CA Thompson A: Impact of Different US Genotypes of Phytophthora infestans on Potato Seed Tuber Rot and Plant Emergence in a Range of Cultivars and Advanced Breeding Lines. Potato Research 2009, 52:121-140.

2. Fry W: Phytophthora infestans: the plant (and R gene) destroyer. Mol Plant Pathol 2008, 9:385-402.

3. McDonald BA, Linde C: Pathogen population genetics, evolutionary potential, and durable resistance. Annu Rev Phytopathol 2002, 40:349-79.

4. Judelson HS, Blanco FA: The spores of Phytophthora: weapons of the plant destroyer. Nat Rev Microbiol 2005, 3:47-58.

5. Kamoun S: A catalogue of the effector secretome of plant pathogenic oomycetes. Annu Rev Phytopathol 2006, 44:41-60.

6. Kamoun S: Groovy times: filamentous pathogen effectors revealed. Curr Opin Plant Biol 2007, 10:358-65.

7. Hogenhout SA, Van der Hoorn RA, Terauchi R, Kamoun S: Emerging concepts in effector biology of plant-associated organisms. Mol Plant Microbe Interact 2009, 22:115-22.

8. Schornack S, Huitema E, Cano LM, Bozkurt TO, Oliva R, Van Damme M, Schwizer S, Raffaele S, Chaparro-Garcia A, Farrer R, et al: Ten things to know about oomycete effectors. Mol Plant Pathol 2009, 10:795-803.

9. Rose JK, Ham KS, Darvill AG, Albersheim P: Molecular cloning and characterization of glucanase inhibitor proteins: coevolution of a counterdefense mechanism by plant pathogens. Plant Cell 2002, 14:1329-45.

10. Tian M, Huitema E, Da Cunha L, Torto-Alalibo T, Kamoun S: A Kazal-like extracellular serine protease inhibitor from Phytophthora infestans targets the tomato pathogenesis-related protease P69B. J Biol Chem 2004, 279:26370-7.

11. Tian M, Kamoun S: A two disulfide bridge Kazal domain from Phytophthora exhibits stable inhibitory activity against serine proteases of the subtilisin family. BMC Biochem 2005, 6:15.

12. Tian M, Win J, Song J, van der Hoorn R, van der Knaap E, Kamoun S: A Phytophthora infestans cystatin-like protein targets a novel tomato papain-like apoplastic protease. Plant Physiol 2007, 143:364-77.

13. Damasceno CM, Bishop JG, Ripoll DR, Win J, Kamoun S, Rose JK: Structure of the glucanase inhibitor protein (GIP) family from phytophthora species suggests coevolution with plant endo-beta-1,3-glucanases. Mol Plant Microbe Interact 2008, 21:820-30.

14. Liu Z, Bos Jl, Armstrong M, Whisson SC, da Cunha L, Torto-Alalibo T, Win J, Avrova AO, Wright F, Birch PR, et al: Patterns of diversifying selection in the phytotoxin-like scr74 gene family of Phytophthora infestans. Mol Biol Evol 2005, 22:659-72

15. Haas BJ, Kamoun S, Zody MC, Jiang RH, Handsaker RE, Cano LM, Grabherr M, Kodira CD, Raffaele S, Torto-Alalibo T, et al: Genome sequence and analysis of the Irish potato famine pathogen Phytophthora infestans. Nature 2009, 461:393-8.

16. Morgan W, Kamoun S: RXLR effectors of plant pathogenic oomycetes. Curr Opin Microbiol 2007, 10:332-8.

17. Birch PR, Armstrong M, Bos J, Boevink P, Gilroy EM, Taylor RM, Wawra S, Pritchard L, Conti L, Ewan R, et al: Towards understanding the virulence functions of RXLR effectors of the oomycete plant pathogen Phytophthora infestans. J Exp Bot 2009, 60:1133-40.

18. Tyler BM, Tripathy S, Zhang X, Dehal P, Jiang RH, Aerts A, Arredondo FD, Baxter L, Bensasson D, Beynon JL, et al: Phytophthora genome sequences uncover evolutionary origins and mechanisms of pathogenesis. Science 2006, 313:1261-6.

19. Win J, Morgan W, Bos J, Krasileva KV, Cano LM, Chaparro-Garcia A, Ammar R, Staskawicz BJ, Kamoun S: Adaptive evolution has targeted the C-terminal domain of the RXLR effectors of plant pathogenic oomycetes. Plant Cell 2007, 19:2349-69.

20. Jiang RH, Tripathy $S$, Govers F, Tyler BM: RXLR effector reservoir in two Phytophthora species is dominated by a single rapidly evolving superfamily with more than 700 members. Proc Natl Acad Sci USA 2008, 105:4874-9.

21. Allen RL, Bittner-Eddy PD, Grenville-Briggs $L$, Meitz JC, Rehmany AP, Rose LE, Beynon JL: Host-parasite coevolutionary conflict between Arabidopsis and downy mildew. Science 2004, 306:1957-60.

22. Rehmany AP, Gordon A, Rose LE, Allen RL, Armstrong MR, Whisson SC, Kamoun S, Tyler BM, Birch PR, Beynon JL: Differential recognition of highly divergent downy mildew avirulence gene alleles by RPP1 resistance genes from two Arabidopsis lines. Plant Cell 2005, 17:1839-50.

23. Gout L, Kuhn ML, Vincenot L, Bernard-Samain S, Cattolico L, Barbetti M, Moreno-Rico O, Balesdent MH, Rouxel T: Genome structure impacts molecular evolution at the AvrLm1 avirulence locus of the plant pathogen Leptosphaeria maculans. Environ Microbiol 2007, 9:2978-92.

24. Yoshida K, Saitoh H, Fujisawa S, Kanzaki H, Matsumura H, Tosa Y, Chuma I, Takano Y, Win J, Kamoun S, et al: Association genetics reveals three novel avirulence genes from the rice blast fungal pathogen Magnaporthe oryzae. Plant Cell 2009, 21:1573-91.

25. Pain A, Bohme U, Berry AE, Mungall K, Finn RD, Jackson AP, Mourier T, Mistry J, Pasini EM, Aslett MA, et al: The genome of the simian and human malaria parasite Plasmodium knowlesi. Nature 2008, 455:799-803.

26. Mueller O, Kahmann R, Aguilar G, Trejo-Aguilar B, Wu A, de Vries RP: The secretome of the maize pathogen Ustilago maydis. Fungal Genet Biol 2008, 45(Suppl 1):S63-70

27. Nielsen $\mathrm{H}$, Brunak $\mathrm{S}$, von Heijne $\mathrm{G}$ : Machine learning approaches for the prediction of signal peptides and other protein sorting signals. Protein Eng 1999, 12:3-9.

28. Menne KM, Hermjakob H, Apweiler R: A comparison of signal sequence prediction methods using a test set of signal peptides. Bioinformatics $2000,16: 741-2$

29. Schneider $G$, Fechner $U$ : Advances in the prediction of protein targeting signals. Proteomics 2004, 4:1571-80.

30. Torto TA, Li S, Styer A, Huitema E, Testa A, Gow NA, van West P, Kamoun S: EST mining and functional expression assays identify extracellular effector proteins from the plant pathogen Phytophthora. Genome Res 2003, 13:1675-85.

31. Dodds PN, Lawrence GJ, Catanzariti AM, Ayliffe MA, Ellis JG: The Melampsora lini AvrL567 avirulence genes are expressed in haustoria and their products are recognized inside plant cells. Plant Cell 2004, 16:755-68.

32. Kemen E, Kemen AC, Rafiqi M, Hempel U, Mendgen K, Hahn M, Voegele RT: Identification of a protein from rust fungi transferred from haustoria into infected plant cells. Mol Plant Microbe Interact 2005, 18:1130-9.

33. Catanzariti AM, Dodds PN, Lawrence GJ, Ayliffe MA, Ellis JG: Haustorially expressed secreted proteins from flax rust are highly enriched for avirulence elicitors. Plant Cell 2006, 18:243-56.

34. Oh SK, Young C, Lee M, Oliva R, Bozkurt TO, Cano LM, Win J, Bos JI, Liu HY, van Damme $M$, et al: In planta expression screens of Phytophthora infestans RXLR effectors reveal diverse phenotypes, including activation of the Solanum bulbocastanum disease resistance protein Rpi-blb2. Plant Cell 2009, 21:2928-47.

35. Lee SJ, Kelley BS, Damasceno CM, St John B, Kim BS, Kim BD, Rose JK: A functional screen to characterize the secretomes of eukaryotic pathogens and their hosts in planta. Mol Plant Microbe Interact 2006, 19:1368-77.

36. Choi J, Park J, Kim D, Jung K, Kang S, Lee YH: Fungal secretome database: integrated platform for annotation of fungal secretomes. BMC Genomics 2010, 11:105.

37. Gotesson A, Marshall JS, Jones DA, Hardham AR: Characterization and evolutionary analysis of a large polygalacturonase gene family in the oomycete plant pathogen Phytophthora cinnamomi. Mol Plant Microbe Interact 2002, 15:907-21.

38. Torto TA, Rauser L, Kamoun S: The pipg1 gene of the oomycete Phytophthora infestans encodes a fungal-like endopolygalacturonase. Curr Genet 2002, 40:385-90.

39. Gaulin E, Drame N, Lafitte C, Torto-Alalibo T, Martinez Y, AmelineTorregrosa C, Khatib M, Mazarguil H, Villalba-Mateos F, Kamoun S, et al: Cellulose binding domains of a Phytophthora cell wall protein are novel pathogen-associated molecular patterns. Plant Cell 2006, 18:1766-77.

40. Tian M, Benedetti B, Kamoun S: A Second Kazal-like protease inhibitor from Phytophthora infestans inhibits and interacts with the apoplastic 
pathogenesis-related protease P69B of tomato. Plant Physiol 2005 138:1785-93.

41. Brunner F, Rosahl S, Lee J, Rudd JJ, Geiler C, Kauppinen S, Rasmussen G, Scheel D, Nurnberger T: Pep-13, a plant defense-inducing pathogenassociated pattern from Phytophthora transglutaminases. Embo J 2002, 21:6681-8.

42. Orsomando G, Lorenzi M, Raffaelli N, Dalla Rizza M, Mezzetti B, Ruggieri S: Phytotoxic protein PcF, purification, characterization, and CDNA sequencing of a novel hydroxyproline-containing factor secreted by the strawberry pathogen Phytophthora cactorum. J Biol Chem 2001, 276:21578-84

43. Gaulin E, Jauneau A, Villalba F, Rickauer M, Esquerre-Tugaye MT, Bottin A: The CBEL glycoprotein of Phytophthora parasitica var-nicotianae is involved in cell wall deposition and adhesion to cellulosic substrates. J Cell Sci 2002, 115:4565-75.

44. Pieterse CM, Derksen AM, Folders J, Govers F: Expression of the Phytophthora infestans ipiB and ipiO genes in planta and in vitro. Mol Gen Genet 1994, 244:269-77.

45. Hunter T: Prolyl isomerases and nuclear function. Cell 1998, 92:141-3.

46. Kiefhaber T, Quaas R, Hahn U, Schmid FX: Folding of ribonuclease T1. 1. Existence of multiple unfolded states created by proline isomerization. Biochemistry 1990, 29:3053-61.

47. Deshpande RA, Shankar V: Ribonucleases from T2 family. Crit Rev Microbiol 2002, 28:79-122.

48. Lacadena J, Alvarez-Garcia E, Carreras-Sangra N, Herrero-Galan E, AlegreCebollada J, Garcia-Ortega L, Onaderra M, Gavilanes JG, Martinez del Pozo A: Fungal ribotoxins: molecular dissection of a family of natural killers. FEMS Microbiol Rev 2007, 31:212-37.

49. Cummins SF, Xie F, de Vries MR, Annangudi SP, Misra M, Degnan BM, Sweedler JV, Nagle GT, Schein CH: Aplysia temptin - the 'glue' in the water-borne attractin pheromone complex. Febs J 2007, 274:5425-37.

50. Latijnhouwers M, Munnik T, Govers F: Phospholipase D in Phytophthora infestans and its role in zoospore encystment. Mol Plant Microbe Interact 2002, 15:939-46.

51. Meijer HJG, Wang S, Bouwmeester K, Govers F: Phytophthora phospholipase $\mathrm{D}$ genes and their role in plant cell degradation. Oomycete Molecular Genetics Network Meeting Asilomar Conference Grounds, Pacific Grove; 2009.

52. Dewey CN, Pachter L: Evolution at the nucleotide level: the problem of multiple whole-genome alignment. Hum Mol Genet 2006, 15(Spec No 1) R51-6.

53. Hachiya T, Osana Y, Popendorf K, Sakakibara Y: Accurate identification of orthologous segments among multiple genomes. Bioinformatics 2009, 25:853-60.

54. Alm RA, Ling LS, Moir DT, King BL, Brown ED, Doig PC, Smith DR, Noonan B, Guild BC, deJonge BL, et al: Genomic-sequence comparison of two unrelated isolates of the human gastric pathogen Helicobacter pylori. Nature 1999, 397:176-80

55. Dobrindt $\mathrm{U}$, Hacker J: Whole genome plasticity in pathogenic bacteria. Curr Opin Microbiol 2001, 4:550-7.

56. Gornhardt B, Rouhara I, Schmelzer E: Cyst germination proteins of the potato pathogen Phytophthora infestans share homology with human mucins. Mol Plant Microbe Interact 2000, 13:32-42.

57. Cvitanich C, Salcido M, Judelson HS: Concerted evolution of a tandemly arrayed family of mating-specific genes in Phytophthora analyzed through inter- and intraspecific comparisons. Mol Genet Genomics 2006, 275:169-84.

58. Gout L, Fudal I, Kuhn ML, Blaise F, Eckert M, Cattolico L, Balesdent MH, Rouxel T: Lost in the middle of nowhere: the AvrLm1 avirulence gene of the Dothideomycete Leptosphaeria maculans. Mol Microbiol 2006, 60:67-80.

59. Fudal I, Ross S, Gout L, Blaise F, Kuhn ML, Eckert MR, Cattolico L, BernardSamain S, Balesdent MH, Rouxel T: Heterochromatin-like regions as ecological niches for avirulence genes in the Leptosphaeria maculans genome: map-based cloning of AvrLm6. Mol Plant Microbe Interact 2007, 20:459-70

60. Parlange F, Daverdin G, Fudal I, Kuhn ML, Balesdent MH, Blaise F, GrezesBesset B, Rouxel T: Leptosphaeria maculans avirulence gene AvrLm4-7 confers a dual recognition specificity by the RIm4 and RIm7 resistance genes of oilseed rape, and circumvents Rlm4-mediated recognition through a single amino acid change. Mol Microbiol 2009, 71:851-63.
61. Hatta R, Ito K, Hosaki Y, Tanaka T, Tanaka A, Yamamoto M, Akimitsu K, Tsuge T: A conditionally dispensable chromosome controls host-specific pathogenicity in the fungal plant pathogen Alternaria alternata. Genetics 2002, 161:59-70.

62. Wittenberg AH, van der Lee TA, Ben M'barek S, Ware SB, Goodwin SB, Kilian A, Visser RG, Kema GH, Schouten HJ: Meiosis drives extraordinary genome plasticity in the haploid fungal plant pathogen Mycosphaerella graminicola. PLOS One 2009, 4:e5863.

63. Ma $\sqcup$, van der Does HC, Borkovich KA, Coleman JJ, Daboussi MJ, Di Pietro A, Dufresne M, Freitag M, Grabherr M, Henrissat B, et al: Comparative genomics reveals mobile pathogenicity chromosomes in Fusarium. Nature 2010, 464:367-73.

64. Galan JE, Collmer A: Type III secretion machines: bacterial devices for protein delivery into host cells. Science 1999, 284:1322-8.

65. Sinzelle L, Izsvak Z, Ivics Z: Molecular domestication of transposable elements: from detrimental parasites to useful host genes. Cell Mol Life Sci 2009, 66:1073-93.

66. van de Lagemaat LN, Landry JR, Mager DL, Medstrand P: Transposable elements in mammals promote regulatory variation and diversification of genes with specialized functions. Trends Genet 2003, 19:530-6.

67. Jurka J: Conserved eukaryotic transposable elements and the evolution of gene regulation. Cell Mol Life Sci 2008, 65:201-4.

68. Naito K, Zhang F, Tsukiyama T, Saito H, Hancock CN, Richardson AO, Okumoto Y, Tanisaka T, Wessler SR: Unexpected consequences of a sudden and massive transposon amplification on rice gene expression. Nature 2009, 461:1130-4.

69. Restrepo S, Myers KL, del Pozo O, Martin GB, Hart AL, Buell CR, Fry WE, Smart CD: Gene profiling of a compatible interaction between Phytophthora infestans and Solanum tuberosum suggests a role for carbonic anhydrase. Mol Plant Microbe Interact 2005, 18 1913-22.

70. Slaymaker DH, Navarre DA, Clark D, del Pozo O, Martin GB, Klessig DF: The tobacco salicylic acid-binding protein 3 (SABP3) is the chloroplast carbonic anhydrase, which exhibits antioxidant activity and plays a role in the hypersensitive defense response. Proc Natl Acad Sci USA 2002, 99:11640-5.

71. Bouarab K, Melton R, Peart J, Baulcombe D, Osbourn A: A saponindetoxifying enzyme mediates suppression of plant defences. Nature 2002, 418:889-92.

72. Grycova L, Dostal J, Marek R: Quaternary protoberberine alkaloids. Phytochemistry 2007, 68:150-75.

73. Supuran CT: Carbonic anhydrases-an overview. Curr Pharm Des 2008, 14:603-14

74. Bednarek P, Osbourn A: Plant-microbe interactions: chemical diversity in plant defense. Science 2009, 324:746-8.

75. Metlen KL, Aschehoug ET, Callaway RM: Plant behavioural ecology: dynamic plasticity in secondary metabolites. Plant Cell Environ 2009, 32:641-53.

76. Tian C, Beeson WT, lavarone AT, Sun J, Marletta MA, Cate JH, Glass NL: Systems analysis of plant cell wall degradation by the model filamentous fungus Neurospora crassa. Proc Natl Acad Sci USA 2009, 106:22157-62.

77. Shah P, Gutierrez-Sanchez G, Orlando R, Bergmann C: A proteomic study of pectin-degrading enzymes secreted by Botrytis cinerea grown in liquid culture. Proteomics 2009, 9:3126-35.

78. Mayans O, Scott M, Connerton I, Gravesen T, Benen J, Visser J, Pickersgill R, Jenkins J: Two crystal structures of pectin lyase A from Aspergillus reveal a $\mathrm{pH}$ driven conformational change and striking divergence in the substrate-binding clefts of pectin and pectate lyases. Structure 1997 5:677-89.

79. Hahn M, Olsen O, Politz O, Borriss R, Heinemann U: Crystal structure and site-directed mutagenesis of Bacillus macerans endo-1,3-1,4-betaglucanase. J Biol Chem 1995, 270:3081-8.

80. Swaminathan S, Eswaramoorthy S: Structural analysis of the catalytic and binding sites of Clostridium botulinum neurotoxin B. Nat Struct Biol 2000, 7:693-9.

81. Barre A, Bourne Y, Van Damme EJ, Peumans WJ, Rouge P: Mannosebinding plant lectins: different structural scaffolds for a common sugarrecognition process. Biochimie 2001, 83:645-51.

82. Popper ZA: Evolution and diversity of green plant cell walls. Curr Opin Plant Biol 2008, 11:286-92. 
83. Juge N: Plant protein inhibitors of cell wall degrading enzymes. Trends Plant Sci 2006, 11:359-67.

84. Galletti R, Denoux C, Gambetta S, Dewdney J, Ausubel FM, De Lorenzo G, Ferrari S: The AtrbohD-mediated oxidative burst elicited by oligogalacturonides in Arabidopsis is dispensable for the activation of defense responses effective against Botrytis cinerea. Plant Physiol 2008, 148:1695-706

85. Cavalier-Smith T: Economy, speed and size matter: evolutionary forces driving nuclear genome miniaturization and expansion. Ann Bot 2005, 95:147-75

86. van der Does HC, Rep M: Virulence genes and the evolution of host specificity in plant-pathogenic fungi. Mol Plant Microbe Interact 2007, 20:1175-82.

87. Westerink N, Brandwagt BF, de Wit PJ, Joosten MH: Cladosporium fulvum circumvents the second functional resistance gene homologue at the Cf-4 locus (Hcr9-4E) by secretion of a stable avr4E isoform. Mol Microbiol 2004, 54:533-45.

88. Rep M, van der Does HC, Meijer M, van Wijk R, Houterman PM, Dekker HL, de Koster CG, Cornelissen BJ: A small, cysteine-rich protein secreted by Fusarium oxysporum during colonization of xylem vessels is required for 1-3-mediated resistance in tomato. Mol Microbiol 2004, 53:1373-83.

89. Farman ML, Eto Y, Nakao T, Tosa Y, Nakayashiki H, Mayama S, Leong SA: Analysis of the structure of the AVR1-CO39 avirulence locus in virulent rice-infecting isolates of Magnaporthe grisea. Mol Plant Microbe Interact 2002, 15:6-16.

90. Orbach MJ, Farrall L, Sweigard JA, Chumley FG, Valent B: A telomeric avirulence gene determines efficacy for the rice blast resistance gene Pita. Plant Cell 2000, 12:2019-32.

91. Cheeseman IH, Gomez-Escobar N, Carret CK, Ivens A, Stewart LB, Tetteh KK, Conway DJ: Gene copy number variation throughout the Plasmodium falciparum genome. BMC Genomics 2009, 10:353.

92. Comeron JM: What controls the length of noncoding DNA? Curr Opin Genet Dev 2001, 11:652-9.

93. Zeh DW, Zeh JA, Ishida Y: Transposable elements and an epigenetic basis for punctuated equilibria. Bioessays 2009, 31:715-26.

94. Emanuelsson $\mathrm{O}$, Brunak S, von Heijne $\mathrm{G}$, Nielsen H: Locating proteins in the cell using TargetP, SignalP and related tools. Nat Protoc 2007, 2:953-71.

95. Bendtsen JD, Nielsen H, von Heijne G, Brunak S: Improved prediction of signal peptides: SignalP 3.0. J Mol Biol 2004, 340:783-95.

96. Plewczynski D, Slabinski L, Tkacz A, Kajan L, Holm L, Ginalski K, Rychlewski L: The RPSP: Web server for prediction of signal peptides. Polymer 2007, 48:5493-5496.

97. Emanuelsson O, Nielsen H, Brunak S, von Heijne G: Predicting subcellular localization of proteins based on their $\mathrm{N}$-terminal amino acid sequence. J Mol Biol 2000, 300:1005-16.

98. Horton P, Park KJ, Obayashi T, Fujita N, Harada H, Adams-Collier CJ, Nakai K: WoLF PSORT: protein localization predictor. Nucleic Acids Res 2007, 35 W585-7.

99. Sonnhammer EL, von Heijne G, Krogh A: A hidden Markov model for predicting transmembrane helices in protein sequences. Proc Int Conf Intell Syst Mol Biol 1998, 6:175-82.

100. Sonnhammer EL, Eddy SR, Durbin R: Pfam: a comprehensive database of protein domain families based on seed alignments. Proteins 1997, 28:405-20.

101. Gough J, Karplus K, Hughey R, Chothia C: Assignment of homology to genome sequences using a library of hidden Markov models that represent all proteins of known structure. J Mol Biol 2001, 313:903-19.

102. Conesa A, Gotz S, Garcia-Gomez JM, Terol J, Talon M, Robles M: Blast2GO: a universal tool for annotation, visualization and analysis in functional genomics research. Bioinformatics 2005, 21:3674-6.

103. Haas BJ, Delcher AL, Wortman JR, Salzberg SL: DAGchainer: a tool for mining segmental genome duplications and synteny. Bioinformatics 2004, 20:3643-6.

104. Li L, Stoeckert CJ Jr, Roos DS: OrthoMCL: identification of ortholog groups for eukaryotic genomes. Genome Res 2003, 13:2178-89.

105. Altschul SF, Madden TL, Schaffer AA, Zhang J, Zhang Z, Miller W, Lipman DJ: Gapped BLAST and PSI-BLAST: a new generation of protein database search programs. Nucleic Acids Res 1997, 25:3389-402.
106. Larkin MA, Blackshields G, Brown NP, Chenna R, McGettigan PA, McWilliam H, Valentin F, Wallace IM, Wilm A, Lopez R, et al: Clustal W and Clustal X version 2.0. Bioinformatics 2007, 23:2947-8.

107. Clamp M, Cuff J, Searle SM, Barton GJ: The Jalview Java alignment editor. Bioinformatics 2004, 20:426-7.

108. Junier T, Pagni M: Dotlet: diagonal plots in a web browser. Bioinformatics 2000, 16:178-9.

109. Bailey TL, Elkan C: Fitting a mixture model by expectation maximization to discover motifs in biopolymers. Proc Int Conf Intell Syst Mol Biol 1994, 2:28-36.

110. Huang CH, Lai WL, Lee MH, Chen CJ, Vasella A, Tsai YC, Liaw SH: Crystal structure of glucooligosaccharide oxidase from Acremonium strictum: a novel flavinylation of 6-S-cysteinyl, 8alpha-N1-histidyl FAD. J Biol Chem 2005, 280:38831-8

111. Winkler A, Lyskowski A, Riedl S, Puhl M, Kutchan TM, Macheroux P, Gruber K: A concerted mechanism for berberine bridge enzyme. Nat Chem Biol 2008, 4:739-41.

112. Sali A, Blundell TL: Comparative protein modelling by satisfaction of spatial restraints. J Mol Biol 1993, 234:779-815.

113. Mallis RJ, Poland BW, Chatterjee TK, Fisher RA, Darmawan S, Honzatko RB, Thomas JA: Crystal structure of S-glutathiolated carbonic anhydrase III. FEBS Lett 2000, 482:237-41.

114. Whittington DA, Waheed A, Ulmasov B, Shah GN, Grubb JH, Sly WS, Christianson DW: Crystal structure of the dimeric extracellular domain of human carbonic anhydrase XII, a bitopic membrane protein overexpressed in certain cancer tumor cells. Proc Natl Acad Sci USA 2001, 98:9545-50.

115. Pettersen EF, Goddard TD, Huang CC, Couch GS, Greenblatt DM, Meng EC, Ferrin TE: UCSF Chimera-a visualization system for exploratory research and analysis. J Comput Chem 2004, 25:1605-12.

doi:10.1186/1471-2164-11-637

Cite this article as: Raffaele et al: Analyses of genome architecture and gene expression reveal novel candidate virulence factors in the secretome of Phytophthora infestans. BMC Genomics 2010 11:637.

\section{Submit your next manuscript to BioMed Central and take full advantage of:}

- Convenient online submission

- Thorough peer review

- No space constraints or color figure charges

- Immediate publication on acceptance

- Inclusion in PubMed, CAS, Scopus and Google Scholar

- Research which is freely available for redistribution

Submit your manuscript at www.biomedcentral.com/submit
C Biomed Central 